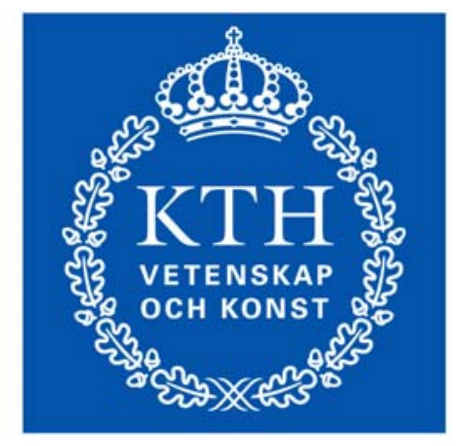

KTH Architecture and the Built Environment

\title{
Influence of Waxes on Bitumen and Asphalt Concrete Mixture Performance
}

\author{
YLVA EDWARDS
}




\begin{abstract}
This doctoral thesis consists of a literature review, presented in two papers, and another six papers describing experimental studies of the influence of different kinds of wax and polyphosporic acid on bitumen and asphalt concrete mixture properties.
\end{abstract}

The literature review should give an extensive description of the field of knowledge concerning wax in bitumen. Effects of wax in crude oil, bitumen and asphalt concrete as well as test methods for studying these effects are described. Theories behind possible mechanisms are also discussed, and commercial wax as additive to bitumen for different purposes included.

The experimental parts comprise laboratory studies involving totally five 160/220 penetration base bitumens from different sources, two isolated bitumen waxes, five commercial waxes and one polyphosphoric acid. Asphalt concrete slabs, containing base or modified bitumen were prepared and tested. Binder properties were evaluated using different types of laboratory equipment, such as dynamic shear rheometer (DSR), bending beam rheometer (BBR), differential scanning calorimeter (DSC), force ductilometer, as well as equipment for determining conventional parameters like penetration, softening point, viscosity, and Fraass breaking point. Fourier Transform Infrared (FTIR) spectroscopy and Thin Layer Chromatography (TLC-FID) were used for chemical characterization. The binders were aged by means of the rolling thin film oven test (RTFOT) and pressure ageing vessel (PAV) in combination. Asphalt concrete properties were evaluated at low temperatures using the tensile strain restrained specimen test (TSRST) and creep test at $-25^{\circ} \mathrm{C}$. Dynamic creep testing was performed at $40^{\circ} \mathrm{C}$, as well as complex modulus tests between 0 and $20^{\circ} \mathrm{C}$.

Binder test results indicated that the magnitude and type of effect on bitumen rheology depend on the bitumen itself, type of crystallizing fraction in the bitumen and/or type and amount of additive used. Bitumen composition was found to be of decisive importance.

Adding polyethylene wax or polyphosphoric acid, especially to a non-waxy $160 / 220$ penetration grade bitumen, showed no or positive effects on the rheological behaviour at low temperatures (decrease in stiffness) as well as medium and high temperatures (increase in complex modulus and decrease in phase angle). However, the corresponding positive effects could not be 
shown in dynamic creep testing (at $40^{\circ} \mathrm{C}$ ) of asphalt concrete mixtures containing these modified binders.

Adding FT-paraffin decreased the physical hardening index for all bitumens. Also polyethylene wax and montan wax showed this effect for some bitumens. Slack wax showed a large increasing effect on physical hardening, and polyphosphoric acid none or a minor negative effect. No correlation between physical hardening index (PHI) and wax content by DSC was found in this study, involving both natural bitumen wax and commercial wax.

Addition of the commercial waxes used showed no or marginally positive influence on bitumen ageing properties for the bitumens and test conditions used.

Comparing asphalt mixture test results to the corresponding binder test results, the effects on asphalt mixtures from adding commercial wax or polyphosphoric acid were less evident. Significant binder physical hardening by BBR could not be confirmed by TSRST.

Keywords: bitumen, asphalt, additives, wax in bitumen, polyphosphoric acid in bitumen, rheology, IR-spectroscopy, dynamic mechanic analysis (DMA), bending beam rheometer (BBR), literature study, low temperature physical hardening, highway materials, morphology, modified bitumens, temperature susceptibility, low temperature performance, ageing, microscopy, chromatography, Fourier transform infrared spectroscopy, force ductility, conventional binder tests, asphalt performance, tensile strain restrained specimen test (TSRST). 
The doctoral thesis contains the following publications:

I Edwards Y., Isacsson U., STATE OF THE ART - "Wax in bitumen Part 1 - Classifications and General Aspects". Road Materials and Pavement Design 6, 3 (2005) 281.

II Edwards Y., Isacsson U., STATE OF THE ART - "Wax in bitumen Part 2 - Characterization and Effects". Accepted for publication in Road Materials and Pavement Design 6, 4 (2005). In press.

III Edwards Y., Redelius P., "Rheological Effects of Waxes in Bitumen". Energy \& Fuels 17, 3 (2003) 511.

IV Edwards Y., Tasdemir Y., Isacsson U., "Rheological effects of commercial waxes and polyphosphoric acid in bitumen 160/220 - High and medium temperature performance". Submitted for publication in Construction and Building Materials.

V Edwards Y., Tasdemir Y., Isacsson U., "Rheological effects of commercial waxes and polyphosphoric acid in bitumen 160/220 - Low temperature performance". Accepted for publication in Fuel 85, (2006). In press.

VI Edwards Y., Tasdemir Y., Isacsson U., "Influence of Commercial Waxes on Bitumen Aging Properties". Accepted for publication in Energy \& Fuels 19, 6 (2005) 2519. In press.

VII Edwards Y., Tasdemir Y., Isacsson U., "Effects of commercial waxes on asphalt concrete performance at low and medium temperatures". Submitted for publication in Cold Regions Science and Technology.

VIII Edwards Y., Tasdemir Y., Isacsson U., "Influence of commercial waxes and polyphosphoric acid on bitumen and asphalt concrete performance at low and medium temperatures". Submitted for publication in Materials and Structures. 


\section{TABLE OF CONTENTS}

Abstract i

1. Introduction 1

2. Literature Review (Papers I and II) 3

2.1 What is wax and wax in bitumen? 3

2.2 Definition and classification of waxes in bitumen 4

2.3 Wax content in bitumen 5

2.4 Effects of wax in bitumen $\quad 7$

2.5 Commercial wax as additive in bitumen 9

3. Materials and procedures (Papers III - VIII) 10

$\begin{array}{ll}3.1 \text { Bitumens and additives } & 10\end{array}$

3.2 Preparation of binder mixtures $\quad 11$

3.3 Methods for binder mixture analysis 11

3.3.1 Dynamic mechanical analysis (DMA) 11

3.3.2 Bending beam rheometer test (BBR) 12

$\begin{array}{ll}3.3 .3 \text { Force ductility } & 12\end{array}$

$\begin{array}{ll}\text { 3.3.4 Differential scanning calorimetry } & 12\end{array}$

3.3.5 Fourier Transform Infrared Spectroscopy 13

3.3.6 Thin Layer Chromatography (TLC-FID) 13

$\begin{array}{ll}3.4 \text { Asphalt concrete mixtures } & 13\end{array}$

$\begin{array}{ll}\text { 3.5 Methods for asphalt concrete mixture analysis } & 14\end{array}$

3.5.1 Tensile Stress Restrained Specimen Test 14

$\begin{array}{ll}\text { 3.5.2 Dynamic creep test } & 14\end{array}$

3.5.3 Complex modulus test $\quad 15$

3.5.4 Creep testing at low temperature $\quad 15$

4. Results and analysis (Papers III - VIII) 15

$\begin{array}{ll}4.1 \text { Binder mixtures (Papers III-VI) } & 15\end{array}$

4.1.1 Empirical measurements (Papers IV and V) 15

4.1.2 DSC measurements 16

4.1.3 Rheological effects at high and medium temperatures 19

4.1.4 Rheological effects at low temperatures $\left(+5^{\circ} \mathrm{C}\right.$ to $\left.-25^{\circ} \mathrm{C}\right) \quad 23$

4.1.5 Effects on irreversible ageing properties (Papers IV, V and VI)26

4.1.6 Effects on low temperature physical hardening 30

4.2 Asphalt concrete mixtures (Papers VII - VIII) 32

4.2.1 Influence of additive on medium temperature performance $\quad 32$

4.2.1 Influence of additive on low temperature performance $\quad 36$ 
5. Discussions 38

5.1 Experimental 40

6. Conclusions 43

7. Acknowledgements 45

8. References 45

$\begin{array}{ll}\text { Abbreviations } & 47\end{array}$

Enclosures (Paper I-VIII) 


\section{Introduction}

Natural wax is part of practically all bitumens and may in different ways affect bitumen properties. Wax has for a long time been of great interest, particularly regarding effects on bitumen quality and methods for determining wax content. Opinions about wax in bitumen have varied over the years and sometimes been contradictory. Already at the first world oil congress in London 1933, the urgent need for a standard method for determining the characteristics and performance of crystallizing and not crystallizing bitumen wax was pointed out.

Through different types of phase transition, natural wax in bitumen may influence binder properties to a larger or minor extent. In some cases, such an influence may give rise to negative effects, as increased sensitivity to cracking or plastic deformation in asphalt concrete pavements. In other cases, wax may show positive effects on bitumen, such as increased stiffness at higher temperatures, leading to improved resistance to rutting. Different methods for determining wax contents give different values for the same bitumen, which is one reason why the opinions concerning effects of wax on bitumen properties have varied so much.

The presence of large wax crystals (macrocrystalline wax) in bitumen is considered to be most problematic. However, waxes in road (penetration grade) bitumen nowadays generally are microcrystalline and/or amorphous and may contain branched, alicyclic and aromatic components with heteroatoms, which renders crystallization considerably more difficult.

Commercial wax, such as FT-paraffin and montan wax, sometimes is added to bitumen or asphalt concrete mixtures in order to obtain certain positive effects. These products are typical so-called flow improvers mainly used for reducing the asphalt mixing temperature in order to reduce energy consumption and emissions, but also to improve workability. However, other effects of different kinds also may result from such wax modification.

The laboratory investigations presented in this thesis were performed in order to better understand the effects of waxes, natural bitumen wax as well as commercial wax, on bitumen and asphalt concrete mixture properties. The softer type of base binder used in the studies (penetration grade $160 / 220$ ) was chosen, since it is frequently used in Sweden, and because the effect of commercial wax (on for instance softening point and penetration) has been reported to decrease with increasing hardness of the bitumen. 
Initially, natural wax in bitumen was the main interest of this project. However, from the literature study (Paper I and II) and first laboratory experiment (Paper III), it was found that natural wax in straight run bitumen today, due to the refinery process, is low in content and of a kind which should not be particularly harmful for binder or asphalt concrete properties, that is to say, no increased sensitivity to, for instance, cracking or plastic deformation in asphalt concrete pavements would normally appear due to natural wax in the bitumen. However, wax could unintentionally be produced through refining procedures like visbreaking or hydrocracking (Redelius 2004).

In the case of blown bitumens and/or wax modified bitumens in road construction (frequently used in the US and Canada in order to fulfil the SHRP binder specifications), the effects on asphalt concrete properties may vary considerably (Hesp 2004). Therefore, commercial wax as an additive to bitumen became of larger interest in the project. In practice, as already mentioned, commercial wax, like FT-paraffin or montan wax, is added to bitumen in order to achieve certain preferred properties like reduced asphalt mixing temperature and higher stiffness of the pavement. Papers IV-VIII deal with the effects of such waxes (and polyphosphoric acid) on binder and asphalt concrete mixture performance.

In the following sections, literature review and laboratory studies are summarized and discussed. The work is described more in detail in the eight enclosed papers. 


\section{Literature Review (Papers I and II)}

The literature review on wax in bitumen is presented in two companion papers, one on classifications and general aspects (Paper I) and another on characterization and effects of wax (Paper II). Paper I contains some sections on wax in petroleum and crude oil, where problems, methods and effects on chemical and rheological performance of the oil are discussed. A general description of mechanisms and effects of wax in bitumen is given, and commercial wax as additive to bitumen is described. The chemical composition and definition of different types of wax, in crude oil as well as in bitumen, is dealt with. In Paper II, methods for the separation of wax, chemical characterization, rheological methods, thermal analysis and crystallography are included. Rheological effects on bitumen caused by wax are described, and possible effects on asphalt concrete mixture performance discussed.

The following short summary of the literature review mainly focuses on some general findings concerning wax and the influence of wax on bitumen and asphalt concrete performance.

\subsection{What is wax and wax in bitumen?}

The English term wax (from Anglo-Saxon weax) was originally applied just to beeswax. In time, the term wax took on a broader significance and became generally applied to wax-like solids and liquids found in nature, as well as components occurring in these materials, such as hydrocarbons, acids, alcohols, and esters with waxy character. Certain synthetic compounds, which chemically are not waxes, but have waxy physical character and technically can be used as a wax substitute, are also included in the wax concept (Warth 1956). There are no evident distinctions between natural and synthetic wax. In general, waxes are indissoluble in water, difficult to dissolve in alcohol and can in melted state be mixed with oil.

Wax is used in a lot of industrial applications, such as production of candles, polishes, crayons, and impregnating substances. Much of this wax comes from petroleum, which is the largest single source of hydrocarbon waxes (Musser et al., 1998). Petroleum wax is a by-product in the petroleum industry. For instance, in order to produce lubricating oil with proper low temperature properties, the wax has to be removed from the oil.

Paraffin rich crude oil is generally considered not quite suitable for bitumen production, but lack of asphaltene rich crude oils may demand the use of 
paraffin naphthenic crude oils as base material at the production of bitumen. However, the wax content as a rule does not constitute any criteria of usefulness at bitumen production, as the wax varies with distillation grade and type of crude oil. The choice of base material for bitumen production is therefore judged by the heavy distillate residue rather than by the crude oil wax content. It has been suggested that wax content in bitumen should not be more than $3 \%$. If this is a relevant figure or not, depends on the definition of wax in bitumen. Isolating wax from bitumen is a process affected by several variables, which is currently not fully understood and controllable. Furthermore, distinct definitions of different wax concepts do not currently exist.

Wax in bitumen has for a long time been of great interest, particularly the effect on bitumen quality and methods for determining wax content (Boucher 1991, Such et al., 2000). Opinions about the effect of wax on bitumen quality have varied over the years and sometimes been contradictory (Barth 1962, Krom 1968, De Bats et al., 1975, Fritsche 1995, Gawel et al., 1998, Planche et al., 1998, Butz et al., 2001, Edwards et al., 2003). Negative effects of wax in bitumen are linked to crystallizing and melting properties. Different types of wax may affect bitumen performance in different ways.

\subsection{Definition and classification of waxes in bitumen}

The definition of bitumen wax has been formulated to facilitate the distinction between harmful wax and less harmful or non-harmful. Often, waxes in bitumen are divided into three general categories: macrocrystalline, microcrystalline and/or amorphous (non-crystalline) wax. Macrocrystalline waxes in bitumen typically have about 30 carbon atoms and crystallize in larger crystals. At 40 or higher numbers of carbon atoms, smaller crystals are formed. Wax with branched carbon chains, aromatic and alicyclic components or heteroatoms show difficulties in crystallizing and are considered as amorphous, ductile or elastic (Boucher 1991). A simplified schematic picture of wax in bitumen is shown in Figure 1, including some general structural formulas for the main chemical components of macro- and microcrystalline wax in bitumen. Composition and properties of these waxes are further discussed in the literature review (Paper I).

Certain components in the bitumen may affect the wax precipitation, implying that different bitumens show different so-called wax-tolerance 
(meaning measure of penetration and viscosity etc. for de-waxed bitumen after addition with selected commercial waxes according to specified method (Boucher 1991)).

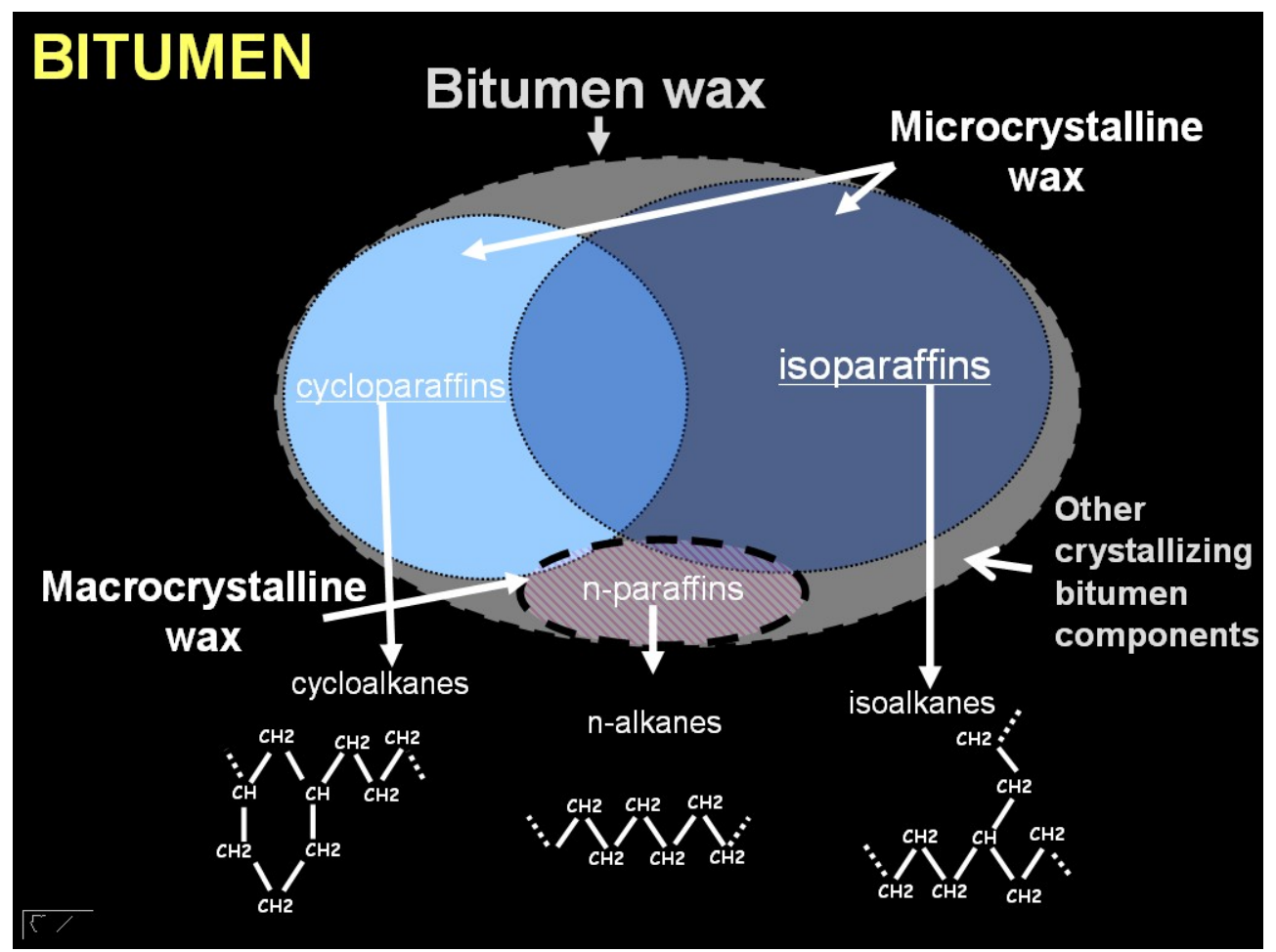

Figure 1. Schematic picture of wax in bitumen (Paper I).

The terms classical and non-classical wax also have been used. Nonclassical wax has been suggested for wax isolated from the SEC (Size Exclusion Chromatography)-II fraction of the bitumen, in contrast to more classical methods with mainly classical wax (n-alkanes) in exchange (Redelius et al., 2002). Yet another classification term used for the total amount of wax in bitumen is crystallizing fraction (CF) by DSC (Differential Scanning Calorimetry).

\subsection{Wax content in bitumen}

Concerning wax content, different methods give different results, which is true for wax quantity as well as quality (Fritsche 1995, Gawel et al., 1997/1998, Krom 1968, Noel et al., 1970, Barth 1962, Edwards et al., 2003, Mózes 1982, Boucher 1991). Over the years, wax content has been 
determined using a lot of different methods/procedures such as the ones listed below:

- German method by Holde (DIN-52015) (destructive distillation method);

- French method (NF-T66);

- Shell method SMS 1769 (SHRP-A-369);

- IR method (Van Doorn 2002, McKay et al., 1995) (the IR regions 750$680 \mathrm{~cm}^{-1}, 940-660 \mathrm{~cm}^{-1}$ and $1800-1530 \mathrm{~cm}^{-1}$ have been used);

- Iatroscan method (Unterleutner et al., 1998) (a correlation between Iatroscan analysis and paraffin wax content according to DIN 52015 has been found);

- Differential Scanning Calorimetry (DSC) (Brulé et al., 1990, Noel et al., 1970, Such et al., 2000, Edwards et al., 2003, Lu et al., 2004);

- Adduct formation with urea (Boucher 1991, Mózes 1982, Barth 1962);

- Dilatation measurements (Krom 1968, Bahia et al., 1992);

- Brightness method (Obertür 1998) (the brightness of bitumen is measured with reflectometer).

In the European binder specification EN 12591 (1999) "Bitumen and bituminous binders - Specifications for paving grade bitumens", two methods for the determination of wax content are included, the distillation method EN 12606-1 and the extraction method 12606-2. The specification standard contains two different requirements (max. 2.2 and 4.5 weight- $\%$, respectively). EN 12606-1 is based on DIN 52015-1980 and EN 12606-2 is based on AFNOR NF T 66-015-1984. In both the EN methods, paraffin wax is defined as "mixture of hydrocarbons crystallizing in an ether/ethanol $50 \%(\mathrm{~V} / \mathrm{V})$ mixture at temperatures down to $-20{ }^{\circ} \mathrm{C}$, obtained by a specified process and having a range of melting of above $25^{\circ} \mathrm{C}$ ". Several European countries (Austria, Denmark, Germany, France and the UK) have in their national specification included wax requirement limits according to either of the two methods. For Sweden, there is a special A-deviation concerning viscosity at $60^{\circ} \mathrm{C}$ allowing higher requirements for viscosity (since low viscosity may be an indication of wax in bitumen). However, the standard is under revision in order to make it more harmonized. In the revised EN 12591 standard (to be published during 2007), both wax content and the A-deviation have been deleted. Furthermore, performance-related 
specifications are under development within CEN TC 336 for possible publication in 2010 or later.

The SHRP binder specification does not include any requirement on wax content. However, Boucher (1991) was of the opinion that wax content as well as wax-tolerance ought to be included, suggesting lower wax content than wax-tolerance as a possible requirement.

One main conclusion to be drawn from the literature study is that wax content in bitumen is not meaningful for specification purposes. Specifying wax criteria on for instance DMA measurements should be more relevant than specifying certain maximum values for wax content by any test method known from the literature. Also, methods used in research for isolating wax from bitumen should be described more in detail, and the wax components obtained chemically characterized and defined in order to distinguish between different types of wax.

\subsection{Effects of wax in bitumen}

Concerning the influence of natural wax on bitumen properties in practice, there are conflicting opinions.

In laboratory studies on bitumen, the effects of wax on traditional bitumen properties have been presented. For instance, it is well known that the effects of wax on bitumen properties such as penetration and viscosity can be illustrated in a Bitumen Test Data Chart (BTDC). In such a chart, the transition range between penetration and viscosity is typical for wax in bitumen, and the crystallization of wax is expressed through the fact that the softening point calculated from viscosity values will be lower than the experimentally determined softening point. Another simple method for demonstrating wax in bitumen could be the difference in viscosity at $60^{\circ} \mathrm{C}$, when tested after heating or after cooling to this temperature. However, these effects will show only in the case of $n$-alkane rich bitumen wax.

Rheometer analyses of different types have been part of many studies. Bitumen analysed in these studies may be divided into three groups:

- Bitumen containing natural wax of different types;

- Bitumen to which natural wax, isolated from bitumen using different procedures, is added;

- Bitumen to which commercial macrocrystalline or microcrystalline wax is added. 
Some of the results obtained in this type of studies are listed below:

- The wax content and type of wax depend on origin (oil crude) and production process. As a rule, distillates from crude oil of naphthenic base type show low content of paraffinic hydrocarbons. Bitumen wax most often is of microcrystalline and/or amorphous type.

- Parameters controlling the effects of wax are chemical composition and rheological properties of the bitumen, amount of wax in the bitumen as well as chemical composition and crystalline structure of the wax. The effect of wax on bitumen is linked to its crystallinity and melting properties. $\mathrm{N}$-alkane rich crystallizing wax in bitumen, as a rule, gives a sudden softening effect at higher temperatures and a stiffening effect at lower temperatures. Crystallizing wax, with no or very low $n$-alkane content, affects the bitumen to a lower extent and, above all, gives a certain stiffening effect below the melting point of the wax.

- Decisive for the effect of wax is the temperature range of application and the definition chosen for the wax in bitumen.

- One reason for the variation of opinions concerning effects of wax in bitumen is the fact that different methods give different results. This is true for wax quantity as well as wax quality. Several methods have been used over the years. Determination of wax content by DSC is mostly reported in recent literature.

- Different bitumens may contain larger or smaller amounts of wax, without their properties being affected in a negative way.

- Few binder studies have been found comparable. Very few scientific studies correlating wax effects in bitumen to the corresponding effects on asphalt mixtures or pavements in the fields have been found.

Amount of heteroatoms, alicyclic and aromatic components in waxes, as well as molecular distribution and carbon chain branching, greatly influence the wax properties. Regarding the effect of wax on bitumen, the temperature range used for the bitumen obviously is of crucial importance, since the crystallizing parts belonging to the different types of waxes show different phase transition areas (crystallization and melting) in bitumen, influencing its rheological properties. Simplifying, waxes in bitumen reduce the stiffness if they remain part of the liquid fraction, but stiffen the bitumen if they separate into solid wax. However, wax in bitumen could disturb the colloidal structure (orientation of polar groups), stability and homogeneity 
of the binder. Additionally, waxy bitumen may harden with time (physical hardening), especially at lower temperatures, possibly initiating cracks in asphalt pavements.

Apparently, the most feared influence of wax in bitumen is the sudden decrease in viscosity due to the melting of crystallized wax, if this phase transition should occur within a temperature range affecting the resistance to permanent deformation of binder and asphalt pavement. Other possible drawbacks are brittleness, physical hardening, poor ductility and poor adhesion. However, results and experience concerning negative effects of wax in bitumen are based mainly on laboratory studies on bitumen and bitumen mixtures, and very few studies concerning effects of waxy bitumens on pavement properties have been reported. Large effects on binders due to wax content must not mean a large influence on asphalt concrete mixture properties (Soenen et al., 2004).

\subsection{Commercial wax as additive in bitumen}

Addition of wax products as flow improver to bitumen has caught the interest of particularly the German asphalt industry (Damm et al., 2002, Butz et al., 2001). Wax as flow improver shows a softening effect on the binder and asphalt mixture at higher temperature. The chief purpose of such an addition is to reduce the mixing temperature of the asphalt in order to reduce the energy consumption and emissions, but also to improve workability and handling. Furthermore, lower void content due to improved compaction should make the pavement more dense and durable. Additional positive effects, such as improved resistance to deformation at higher temperatures for bitumen and asphalt concrete have been reported as well. However, low temperature performance and effects on fatigue and adhesion properties are less investigated. Typical viscosity lowering additives used for bitumen are FT-paraffin, montan wax based products, oxidized polyethylene wax, thermoplastic resins and fatty acid amide. Molecular weight distributions of such products differ a lot.

Already in 1922, the German chemist Frans Fischer and his Czech colleague Hans Tropsch developed a procedure for producing liquid fuel from coal by heating it under pressure, obtaining a mixture of carbon monoxide and hydrogen gas. By leading the mixture over metal catalysts and pumping in more hydrogen gas, chemical reactions start building up long hydrocarbon chains. FT-paraffin for bitumen modification mainly consists of hydrocarbon chains with 40 to 100 carbon atoms. The congealing point is 
about $100^{\circ} \mathrm{C}$ and the product melts between about 70 and $120^{\circ} \mathrm{C}$. Montan wax is a fossil ester wax obtained from brown coal. It shows a more complicated chemical structure compared to FT-paraffin.

\section{Materials and procedures (Papers III - VIII)}

\subsection{Bitumens and additives}

Totally five bitumens of the same penetration grade, 160/220, and different origins were used for the studies. Two of the bitumens were non-waxy and the other three contained $2-4 \% \mathrm{wt}$ natural wax by DSC. Bitumen characteristics are given in the different papers.

The additives used were two natural bitumen waxes, slack wax, FT-paraffin (Sasobit), montan wax (Asphaltan B), polyethylene wax (Luwax A) and polyphosphoric acid (Innovalt N200).

The natural bitumen waxes added were isolated from the SEC-II fractions of the two waxy bitumens used. Characteristics of these bitumen waxes are given in Paper III. The composition of the two bitumen waxes was chemically different, containing no or very little $n$-alkanes.

The slack wax, used in Paper III, was a commercially available product (Terhell Paraffin Type JA 201 from Hans-Otto Schumann GmbH\& Co) with a congealing point of $41-42^{\circ} \mathrm{C}$ and mainly composed of $n$-alkanes. A very similar slack wax product (Sasolwax 4442 from Sasol) with a congealing point of $43-47^{\circ} \mathrm{C}$ was used in Paper VIII. The reason for not using the Terhell Paraffin in both studies was that for the later study in Paper VIII, Terhell Paraffin was no longer available.

FT-paraffin and montan wax are so-called bitumen flow improvers with congealing or solidification points of about $100^{\circ} \mathrm{C}$. The products were supplied by Sasol Wax $\mathrm{GmbH}$ and Romonta $\mathrm{GmbH}$, respectively. As already mentioned (cf. Section 2.5), such viscosity depressants sometimes are used for asphalt pavements and mastic asphalt to reduce the mixing temperature and thereby energy consumption and emissions. Certain stiffening effects may be obtained as well.

The polyethylene wax is a type of product normally not used as additive to bitumen, generally showing a congealing point of $92-100^{\circ} \mathrm{C}$. It was supplied for the study by Sasol. 
Finally, the polyphosphoric acid used is a bitumen modifier aimed for improving high and low temperature performance. Obviously, this is not a wax product. The reason for using polyphosphoric acid in some of the studies (Papers IV, V and VIII) was that its effects on binder properties have been reported to be similar to those of the commercial waxes used. Characteristics are reported in Paper IV and V. The product was supplied for the study by Rhodia.

\subsection{Preparation of binder mixtures}

Samples were prepared by adding calculated amount of additive to approximately $250 \mathrm{~g}$ of bitumen, after which the sample was heated $30 \mathrm{~min}$ at $155{ }^{\circ} \mathrm{C}$. The samples were then placed in preheated blocks and homogenized by shaking $90 \mathrm{~s}$. Levels of 3 and $6 \% \mathrm{wt}$ wax were used. For polyphosphoric acid the levels were 0.4 and $1 \%$ wt.

In some cases (Papers IV-VI), samples were aged using the RTFOT (rolling thin film oven test) followed by PAV (pressure ageing vessel) according to SHRP specifications. Ageing in PAV was performed at $90^{\circ} \mathrm{C}$. Aged binders were evaluated by rheological and chemical measurements.

\subsection{Methods for binder mixture analysis}

Methods used for binder analysis were rheological methods (dynamic mechanical analysis (DMA), bending beam rheometer (BBR), softening point (EN 1427), penetration at $25^{\circ} \mathrm{C}$ (EN 1426), dynamic viscosity (EN 12596), kinematic viscosity (EN 12595), breaking point Fraass (EN 12593) and force ductility (EN 13589)), differential scanning calorimetry (DSC) and methods for chemical characterization (Fourier transform infrared (FTIR) spectroscopy and thin layer chromatography (TLC-FID)). These tests are described in Papers III-VI. Short descriptions of some of the methods also are given in the following sections.

\subsubsection{Dynamic mechanical analysis (DMA)}

Rheological measurements were performed with temperature sweeps using a rheometer (Rheometrics, RDA II). Experiments were carried out in the temperature range of $-30^{\circ} \mathrm{C}$ to $+100^{\circ} \mathrm{C}$. For the temperature range -30 to $+80^{\circ} \mathrm{C}$, parallel plates with $8 \mathrm{~mm}$ diameter and gap $1.5 \mathrm{~mm}$ were used, while for the range 10 to $100^{\circ} \mathrm{C}$, the plate diameter was $25 \mathrm{~mm}$ and the gap $1 \mathrm{~mm}$. The temperature sweeps started at the lower temperature, and the temperature was increased by $2^{\circ} \mathrm{C} / \mathrm{min}$. A sinusoidal strain was applied, and 
the actual strain and torque were measured. Dynamic shear modulus $\left|G^{*}\right|$, phase angle $\delta$, and $\mathrm{G}^{*} / \sin \delta$ were calculated. The frequencies used were 10 $\mathrm{rad} / \mathrm{s}$ for the temperature range of -30 to $+80^{\circ} \mathrm{C}$ and 1 and $0.1 \mathrm{rad} / \mathrm{s}$ for the temperature range of +10 to $+100^{\circ} \mathrm{C}$. In Paper III, also frequency sweeps from 0.1 to $100 \mathrm{rad} / \mathrm{s}$ were performed.

\subsubsection{Bending beam rheometer test (BBR)}

Creep tests were carried out using the bending beam rheometer (TE-BBR, Cannon Instrument Company). Test temperatures used were from -15 to $-35^{\circ} \mathrm{C}$. A sample beam (125 mm long $12.5 \mathrm{~mm}$ wide and $6.25 \mathrm{~mm}$ thick) was submerged in a constant temperature bath and kept at test temperature for $60 \mathrm{~min}$. A constant load of $100 \mathrm{~g}$ was then applied to the beam of the binder, which was supported at both ends, and the deflection of centre point was measured continuously. Creep stiffness $(\mathrm{S})$ and creep rate $(\mathrm{m})$ of the binders were determined at a loading time of $60 \mathrm{~s}$. Physical hardening after $24 \mathrm{~h}$ at $-25^{\circ} \mathrm{C}$ was determined as well (Paper V).

\subsubsection{Force ductility}

Force ductility testing was performed at $+5^{\circ} \mathrm{C}$ and $50 \mathrm{~mm} / \mathrm{min}$ using a Strassentest Baustoff system. Test specimens were stretched up to break or until constant registered zero force. Maximum load was registered. Deformation energy was calculated for original samples, but not for aged samples, as break occurred in some cases before the recorded force reached zero, and calculations therefore became not relevant.

\subsubsection{Differential scanning calorimetry}

DSC analysis was performed using a Mettler TA3000 system. Approximately $15 \mathrm{mg}$ of bitumen sample was weighed in an open pan and placed in the DSC cell under nitrogen blanket. The sample was heated to $+110^{\circ} \mathrm{C}$ and then cooled at $10^{\circ} \mathrm{C} / \mathrm{min}$ to $-110^{\circ} \mathrm{C}$, followed by heating to $+110^{\circ} \mathrm{C}$ at the same rate. For samples containing FT-paraffin, montan wax or polyethylene wax, the heating temperature $160^{\circ} \mathrm{C}$ had to be chosen for the dissolution to be completed. The method was used for determining the DSC wax content of the prepared bitumen/wax samples. Both cooling and heating cycles were used for calculation of the amount of crystallizing material (crystallizing material in the cooling cycle plus re-crystallizing material in the heating cycle, or melting material in the heating cycle). Other parameters registered in the analysis were the starting temperature of 
crystallization, the wax melting out temperature and the temperature at exothermic and endothermic peak heat flow. For the calculation of amount of wax, a value of $\Delta \mathrm{H}=121.3 \mathrm{~J} / \mathrm{g}$ was used. This figure is an estimated average value for natural wax in bitumen (Redelius 2004).

\subsubsection{Fourier Transform Infrared Spectroscopy}

An FTIR spectrometer, Infinity 60AR (Mattson resolution $0.125 \mathrm{~cm}^{-1}$ ), was used to investigate functional groups of wax modified binders before and after ageing. $5 \% \mathrm{wt}$ solutions of binder samples were prepared in carbon disulfide. Scans were performed using circular sealed cells (ZnSe windows and $1 \mathrm{~mm}$ thickness). All spectra were obtained by 32 scans with $5 \%$ iris and $4 \mathrm{~cm}^{-1}$ resolution in wave numbers from 4000 to $500 \mathrm{~cm}^{-1}$. Peaks of IR absorbance from 750 to $680 \mathrm{~cm}^{-1}$ were used as an indication of amorphous and/or crystalline structures in the binder due to wax content. Peaks at 1705 and $1030 \mathrm{~cm}^{-1}$ show bitumen carbonyl compounds and sulfoxides, respectively, and were used to characterize bitumens of the wax modified binders and as an indication of ageing.

\subsubsection{Thin Layer Chromatography (TLC-FID)}

Iatroscan MK-5 analyzer (Iatron Laboratories Inc., Tokyo, Japan) was used for determining generic fractions of the wax modified binders before and after ageing. $2 \%(\mathrm{w} / \mathrm{v})$ solutions of bitumen were prepared in dichloromethane, and $1 \mu \mathrm{l}$ sample solution spotted on chromarods. Bitumen was separated into four generic fractions (saturates, aromatics, resins and asphaltenes) using $n$-heptane, toluene and dichloromethane/methanol (95/5), respectively, in a three-step eluting process.

\subsection{Asphalt concrete mixtures}

Dense graded asphalt concrete with maximum aggregate size of $11 \mathrm{~mm}$ and nominal binder content $6.2 \%$ by weight was prepared for the studies in Papers VII and VIII. A crushed granite material was used. The target air void content was $2.0-3.5 \%$ by volume. The mixtures were manufactured by Nynas, and compacted to slabs using a laboratory rolling wheel compactor (MAP Spechbach-le-bas, France). The final dimensions of each slab were $600 \mathrm{~mm} \times 400 \mathrm{~mm} \times 100 \mathrm{~mm}$. Five slabs were prepared for the study in Paper VII and eight for the study in Paper VIII. The temperature for mixing and compaction was $155^{\circ} \mathrm{C}$. From each slab, cylindrical specimens were cored for different types of testing. 


\subsection{Methods for asphalt concrete mixture analysis}

Methods used for testing asphalt concrete mixture properties were tensile stress restrained specimen test (TSRST), dynamic creep test and complex modulus test. Also, creep testing at $-25^{\circ} \mathrm{C}$ was carried out for the NB and slack wax modified NB mixture in Paper VIII. In Paper VII, TSRST specimens were subjected to thermal ageing in a draft oven at $85^{\circ} \mathrm{C}$.

\subsubsection{Tensile Stress Restrained Specimen Test}

For the TSRST equipment used, the main parts are environmental chamber, load frame, screw jack, cooling device, temperature controller, and data acquisition and control system. The test specimen is glued to two aluminium plates and mounted in the load frame. Before performing the test, the specimen was kept for one hour at approximately $2^{\circ} \mathrm{C}$ in the environmental chamber to ensure that the inside temperature of the specimen was the same as the temperature of the environmental chamber. The cooling rate was $10^{\circ} \mathrm{C} / \mathrm{h}$. The contraction of the specimen during the cooling process was measured using two linear variable differential transducers (LVDT). Initially, due to relaxation of the specimen, a relatively slow increase in thermal stress can be observed. As the temperature is decreased to a certain level, the thermally induced stress becomes almost linearly related to the temperature, until fracture of the specimen occurs at the fracture temperature and maximum stress value (fracture strength).

Specimens were also cooled unrestrained to $-25^{\circ} \mathrm{C}$ and held for 3 and $24 \mathrm{~h}$, after which they were strained and tested according to the procedure described above, starting at $-25^{\circ} \mathrm{C}$.

\subsubsection{Dynamic creep test}

This repeated load axial test was performed using a Nottingham asphalt tester. Cylindrical specimens were exposed to uniaxial, periodically repeated loading consisting of a 1 -second loading $(100 \mathrm{kPa})$ and a 1 -second rest. The test was carried out at $40^{\circ} \mathrm{C}$ using 3600 pulses. The deformation in the direction of the loading was measured as a function of the number of loadings. The deformation remaining after testing was stated as permanent deformation. The creep rate was calculated. The test was performed according to a Swedish standard test method (FAS 468), using a loading plate with diameter of $100 \mathrm{~mm}$ (i.e. smaller than the specimen diameter, which was $150 \mathrm{~mm}$ ). 


\subsubsection{Complex modulus test}

Complex modulus was investigated using un-confined uniaxial tension and compression tests. A servo-hydraulic testing system (MTS 810, Teststar II) was used. The specimens were subjected to sinusoidal oscillating axial loading in both tension and compression at constant $\left(50 \cdot 10^{-6} \mathrm{~m} / \mathrm{m}\right)$ amplitude. The specimens were tested at three temperatures $(0,10$ and $\left.20^{\circ} \mathrm{C}\right)$. At each temperature, a frequency sweep of nine frequencies $(40,32$, $16,8,4,2,1,0.5$ and $0.1 \mathrm{~Hz})$ was performed. Dynamic modulus, $\left|\mathrm{E}^{*}(\omega)\right|$, and phase angle, $\varphi(\omega)$, were obtained as well as Poisson ratio, $v$. Data were used to construct dynamic modulus and phase angle master curves.

\subsubsection{Creep testing at low temperature}

Creep testing was performed at $-25^{\circ} \mathrm{C}$ in uni-axial compression. The stress was applied in one step and held constant for $240 \mathrm{~s}$. The creep compliance $\mathrm{D}(\mathrm{t})$ was calculated as

$$
\begin{aligned}
& D(t)=\frac{\varepsilon}{\sigma_{0}} \\
& \sigma_{0}=1000 \mathrm{kPa}
\end{aligned}
$$

To ensure that thermal equilibrium, the specimen was kept at the testing temperature for $3 \mathrm{~h}$ before the creep test started. Measurements were then made after 7, 11, 15, 19 and $23 \mathrm{~h}$ at the test temperature used.

\section{Results and analysis (Papers III - VIII)}

\subsection{Binder mixtures (Papers III-VI)}

\subsubsection{Empirical measurements (Papers IV and V)}

Adding commercial wax to bitumen showed an increase in binder stiffness expressed in terms of penetration and softening point. The changes increased with additive content but varied with bitumen source and type of additive. Adding FT-paraffin showed the highest effect, followed by montan wax and polyethylene wax. For instance, adding $6 \%$ of FT-paraffin to nonwaxy bitumen made the softening point increase from 38 to $96^{\circ} \mathrm{C}$ and the penetration decrease from 173 to $68 \mathrm{dmm}$. Adding polyphosphoric acid also made the bitumen stiffer, but to a minor extent. Penetration index PI (by 
Pfeiffer and Van Doormal) was considerably increased by the addition of commercial waxes, up to positive values of about 7. Although PI frequently is used as approximation of expected temperature susceptibility for bitumen, it could for waxy or wax modified bitumens give incorrect indications. The formula used presupposes that the binder has a penetration value of 800 $\mathrm{dmm}$ at its softening point, which is normally not known and therefore makes the PI very sensitive to variations in softening point. PI for base penetration bitumens normally ranges from about -3 (for highly temperature susceptible bitumens) to about +7 for highly blown (low-temperature susceptible) bitumens.

Adding FT-paraffin or montan wax generally increased Fraass breaking point of the binders (performed on aged samples), while adding polyethylene wax or polyphosphoric acid showed smaller effects. The largest increase in breaking point $\left(6^{\circ} \mathrm{C}\right)$ was obtained from adding $6 \%$ FTparaffin to two of the base bitumens. For no additive, but possibly PPA ( $1 \%)$, the breaking point was significantly decreased (Paper V). However, as described in Paper VIII, adding polyethylene wax, slack wax and polyphosphoric acid, respectively, to the non-waxy bitumen used decreased the breaking point by approximately 3 to $4{ }^{\circ} \mathrm{C}$. In this case measurements were performed on non-aged samples.

Viscosity at $60^{\circ} \mathrm{C}$ was decreased only by the addition of slack wax (Paper VIII). In all other cases, viscosity was increased, and most by the addition of FT-paraffin.

\subsubsection{DSC measurements}

DSC curves from bitumens are comparably complicated, since there may be several overlapping phenomena to consider. The glass transition of bitumen occurs over a large temperature range due to the complex mixture of different molecules. Starting at a lower temperature range of the heat flow DSC diagram, the glass transition shows as a shift in specific heat versus temperature. The glass transition may be followed by a weak exothermic effect caused by the cold crystallization of wax, which could not crystallize through the cooling cycle due to limited mobility. This effect did not occur for non-waxy bitumen containing commercial wax (FT-paraffin, montan wax or polyethylene wax), but did occur for waxy bitumen with or without commercial wax additive. Consequently, all three commercial waxes crystallized through the cooling cycle and did not show any additional exothermic effect in the heating cycle due to re-crystallization. Mixtures 
containing polyphosphoric acid did not show any thermal effects at all due to the presence of this additive.

A broad endothermic effect may also be observed in the DSC heat flow diagram due to the melting of crystallizing fractions or other phenomena. This peak differs mostly depending on type of wax. For bitumen containing slack wax, the peak was very pronounced, while for bitumen containing solely natural bitumen wax, the peak profile was broader and showed no pronounced peak (most likely due to lack of $n$-alkanes) or (if containing some $n$-alkanes), the profile was a combination of a pronounced and broader peak. This is illustrated in Figure 2, showing heating scans for binder mixtures containing added natural bitumen wax or slack wax.

In the range of 60 to $90^{\circ} \mathrm{C}$, natural bitumen wax is normally completely melted out. However, for the commercial waxes used in these binder studies, the melting out temperatures of the bitumen/wax mixtures were higher (between approximately 100 and $130^{\circ} \mathrm{C}$ ). For slack wax, the melting temperature range was comparably narrow and the wax melted out at a considerably lower temperature.

The determined crystallizing fraction (CF) by DSC was higher than expected (natural wax content by DSC + added amount of wax) for all binder mixtures containing FT-paraffin, which could mainly be explained by the fact that the same enthalpy value $\left(\operatorname{wax}(\%)=\frac{\text { melting enthalpy }}{121.3} \cdot 100\right)$ was used for all binder samples. For instance, adding $6 \%$ wt FT-paraffin to non-waxy bitumen (NV) gave a $\mathrm{CF}$ value of $10.5 \%$. Binders containing polyethylene wax, on the other hand, showed lower values and binders containing montan wax approximately expected values. For binders containing added bitumen wax or slack wax, the determined crystallizing fractions were lower than expected, indicating certain dissolution of added wax. (In this connection it is interesting to notice that if a microcrystalline wax is added to melted macrocrystalline wax, it behaves like a solution. The melting point of the wax mixture is increased and the crystallization of the macrocrystalline wax inhibited (Warth 1956)). However, for the non-waxy bitumen NB (Paper VIII), adding montan wax or slack wax gave higher values than expected, indicating differences in chemical composition between the two different non-waxy bitumens used. As already mentioned, the binders containing polyphosphoric acid did not show any thermal effects due to the presence of this additive. 


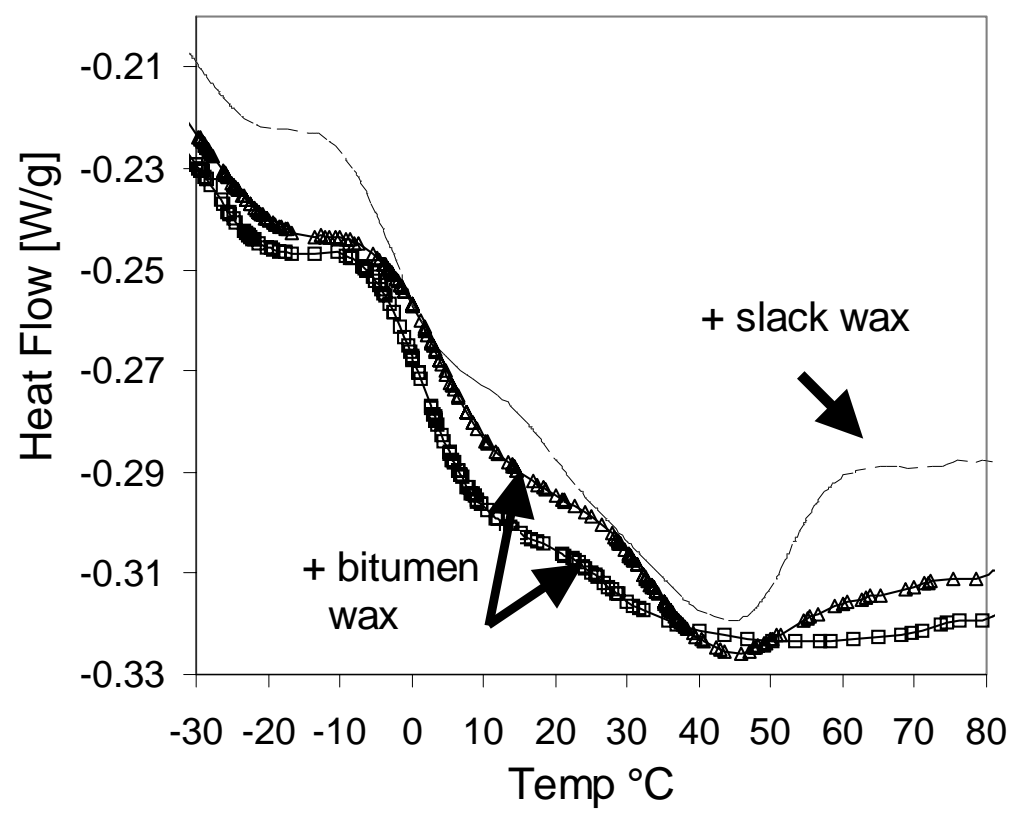

Figure 2. Heat flow in heating cycle by DSC for bitumen ME containing different types of wax (Paper III).

Depending on molecular weight distribution, the wax melting temperature range differed between the different binder mixtures and was considerably broader for montan wax and FT-paraffin wax than for polyethylene wax, natural wax, and slack wax. Polyethylene wax showed a more narrow melting temperature range, compared to FT-paraffin and montan wax, starting at about $70^{\circ} \mathrm{C}$. This is shown in Figure 3. 


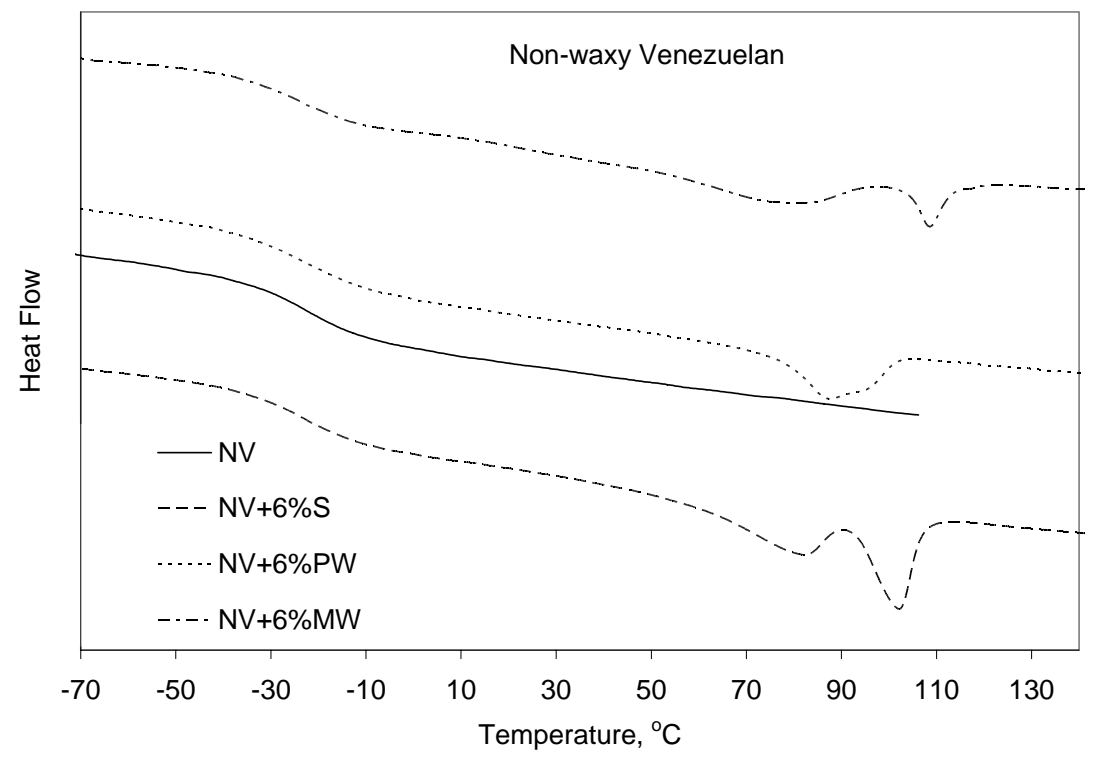

Figure 3. Heat flow by DSC, showing the melting process of bitumen NV containing $6 \%$ wt wax S, MW and PW, respectively (Paper IV).

Possible relationships between DSC and empirical testing parameters for binders containing wax additive (FT-paraffin, montan wax or polyethylene wax) were investigated in Paper IV. The best correlation was found between temperature at exothermic peak heat flow by DSC and penetration index PI $\left(\mathrm{R}^{2}=0.92\right)$ or softening point $\left(\mathrm{R}^{2}=0.86\right)$. Determined amount of crystallizing fraction by DSC could best be correlated to force ductility maximum load at $+5^{\circ} \mathrm{C}\left(\mathrm{R}^{2}=0.72\right)$. The highest PI values (around 7) were obtained by the addition of FT-paraffin or montan wax.

\subsubsection{Rheological effects at high and medium temperatures}

Rheological effects at high and medium temperatures of adding wax to bitumen were studied using DMA (Paper III and IV). In DMA, the ratio of peak stress to peak strain is defined as the complex modulus $\left|G^{*}\right|$, which is a measure of the overall resistance to deformation of the sample tested. The phase difference between stress and strain is defined as the phase angle $\delta$, and is a measure of the viscoelastic character of the sample. For a completely viscous liquid, the phase angle is $90^{\circ}$ and for an ideal elastic solid material, the phase angle is $0^{\circ}$. Complex modulus and phase angle of bitumens are functions of temperature and frequency, which may be 
changed by the addition of different additives such as waxes, polymers and acids.

In Paper III, bitumen mixtures containing added natural bitumen wax or slack wax were studied, and in Paper IV mixtures containing commercial wax or polyphosphoric acid. In both studies, magnitude and type of effect were found to depend on the bitumen itself as well as type and amount of additive. Adding slack wax gave markedly negative effects by lowering the complex modulus at temperatures over about $40^{\circ} \mathrm{C}$ (cf. Figure 4). At higher wax levels, a pronounced deviation from the smooth phase angle curve and corresponding plateau effect for the complex modulus appeared at low frequency. Adding bitumen wax (with no or very low $n$-alkane content) gave no negative complex modulus lowering effect at higher temperatures. However, stiffening effects occurred below about $50^{\circ} \mathrm{C}$.

In the case of commercial waxes and polyphoshoric acid, temperature sweeps showed the highest stiffening effects from adding polyethylene wax or polyphosphoric acid in the temperature range from about +25 to $90^{\circ} \mathrm{C}$ (cf. Figure 5). The high effect from adding polyethylene wax may partly be explained by its more narrow melting temperature range compared to FTparaffin or montan wax, as well as the ability to form an elasticity improving crystal and/or gel network. The effect was more evident at lower frequency. None of the commercial waxes or polyphosphoric acid showed any sudden complex modulus lowering effect at higher temperatures, thereby possibly affecting the resistance to permanent deformation, as for waxes containing $n$-alkanes. Stiffening effects occurred at temperatures below $90^{\circ} \mathrm{C}$. However, at temperatures higher than $90^{\circ} \mathrm{C}$, FT-paraffin and montan wax, being used as flow improvers, showed viscosity lowering effects due to high melting temperatures of some parts of these waxes. Such effects were not investigated in any of the studies.

In Paper III, the slope of the logarithmic function of the complex modulus between 25 and $60^{\circ} \mathrm{C}$ was suggested as a factor of rutting sensitivity (cf. Figure 6). However, both the positive stiffening effect in one part of the temperature range and the sudden negative decreasing viscosity effect in the other part of the temperature range will contribute to the decrease of such a value, which may be misleading. Adding natural bitumen wax (Paper III) or slack wax (Paper III and VIII) increased the negative slope value, most for slack wax. Adding montan wax showed the same effect but to a minor extent, while adding FT-paraffin, either slightly increased or decreased the 
slope, depending on base bitumen. Adding polyethylene wax or polyphosphoric acid decreased the negative slope in all cases.

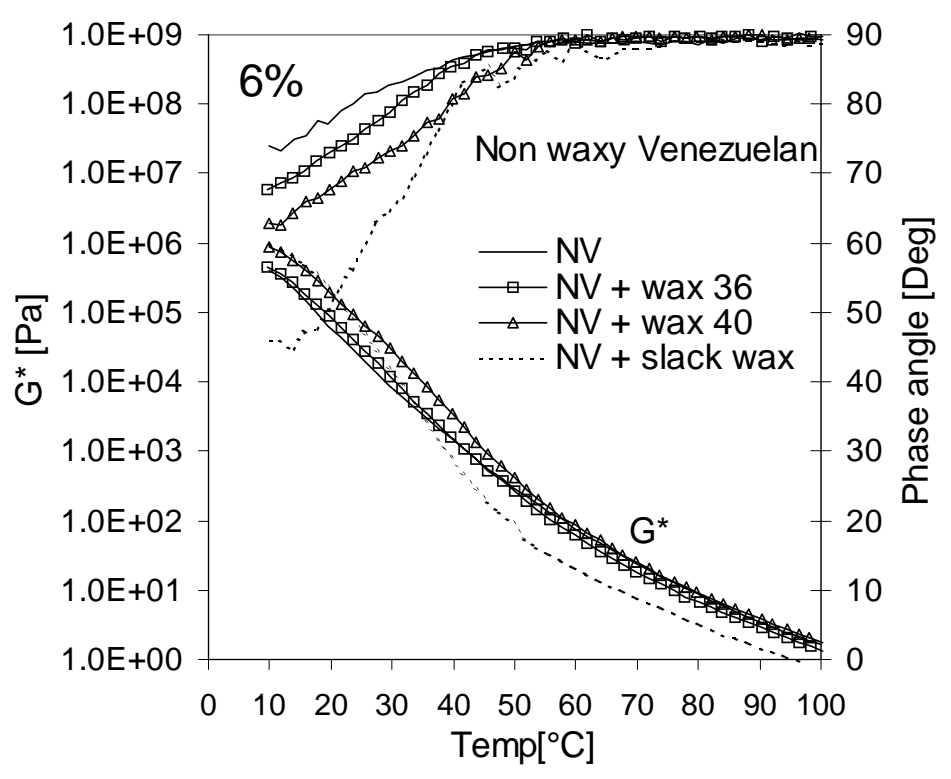

Figure 4. Influence on complex modulus and phase angle (frequency $1 \mathrm{rad} / \mathrm{s}$ ) on the non-waxy bitumen $N V$ due to the addition of natural bitumen wax or slack wax (Paper III).

In Paper VIII, adding the same types of commercial wax, polyphosphoric acid and slack wax to the non-waxy $160 / 220$ penetration grade bitumen (NB) showed similar effects by DMA as for the non-waxy bitumen NV referred to above. However, the effects from adding polyethylene wax were less pronounced for NB than for NV and the effects from adding slack wax more devastating by a sudden decrease in complex modulus already at about $25^{\circ} \mathrm{C}$. This is illustrated in Figures 4 and 5. Comparing curves in Figure 5, the modulus of NB is less increased by the addition of polyethylene wax than the modulus of NV over approximately the same higher temperature range. The different behaviour probably is linked to differences in molecular associations between wax and bitumen, indicating a stronger kind of network for the NV mixture (lower phase angle). Concerning the influence of slack wax on NV and NB, the differences between binder mixtures could be due to several reasons such as melting point range, solubility and chemical composition. This is further discussed in Chapter 5. 

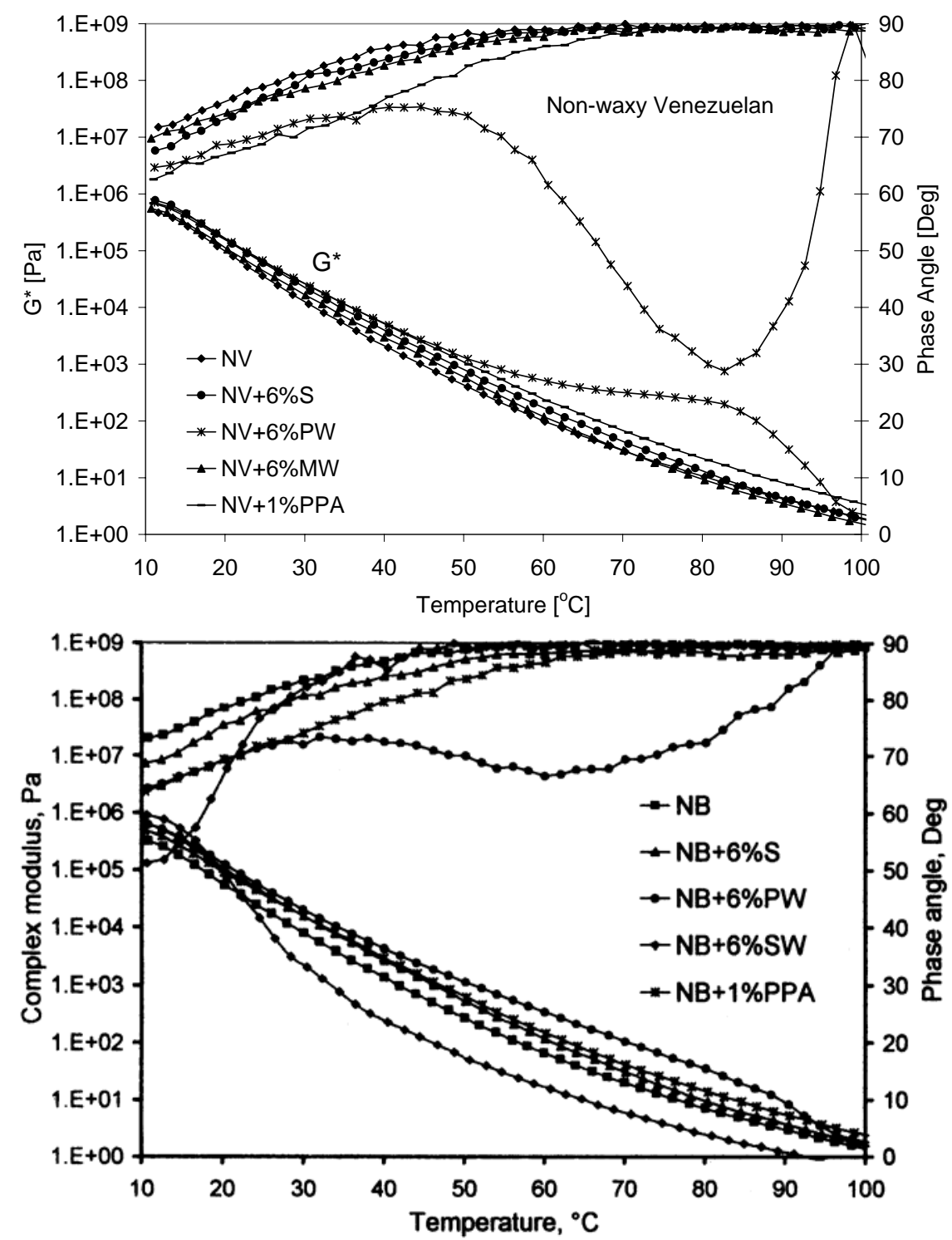

Figure 5. Influence on complex modulus and phase angle (frequency $1 \mathrm{rad} / \mathrm{s}$ ) on the two different non-waxy bitumens $N V$ and NB due to the addition of commercial wax or polyphosphoric acid (Papers IV and VIII). 


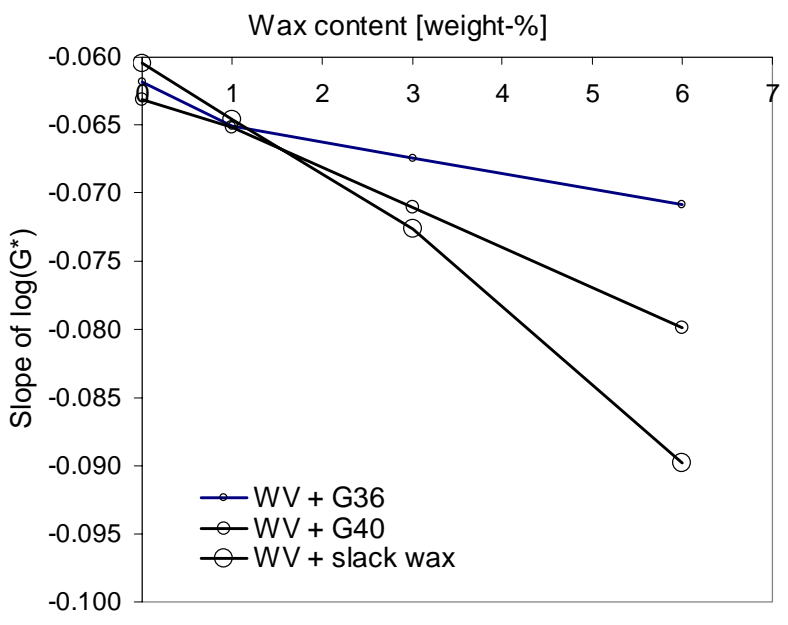

Figure 6. Slope of logarithm of complex modulus between 25 and $60^{\circ} \mathrm{C}$ for one bitumen at different wax levels (Paper III).

\subsubsection{Rheological effects at low temperatures $\left(+5^{\circ} \mathrm{C}\right.$ to $\left.-25^{\circ} \mathrm{C}\right)$}

The influence of adding wax or acid on the low-temperature performance of bitumens was studied using DMA, BBR, and force ductility measurements. Too high a binder modulus at low temperatures could make the asphalt concrete sensitive to thermal and load induced cracking. A major factor determining the susceptibility of a pavement to thermal cracking is the ability of the binder to withstand or relieve thermal stresses before a certain critical level is reached, where cracks appear.

DMA results (Paper III and V) showed that adding natural wax or slack wax gave a stiffening effect down to at least $-5^{\circ} \mathrm{C}$, indicating possible lower resistance to cracking at these temperatures. However, adding slack wax showed a decreasing effect on the stiffness of the non-waxy bitumen at temperatures lower than $-5^{\circ} \mathrm{C}$. BBR analysis at $-15,-20$ and $-25^{\circ} \mathrm{C}$ gave the same indication, i.e. the non-waxy bitumen became more flexible. Also, according to results in Paper VIII, adding slack wax to non-waxy bitumen (NB) decreased the BBR stiffness at $-25^{\circ} \mathrm{C}$. However, at $-20^{\circ} \mathrm{C}$, this behaviour was not shown. Also adding PPA to this particular non-waxy bitumen made the BBR stiffness decrease (at both -25 and $-20^{\circ} \mathrm{C}$ ).

Adding FT-paraffin, montan wax or polyethylene wax showed noticeable stiffening effect at temperatures down to at least $+5^{\circ} \mathrm{C}$ for all the bitumens studied. Adding polyphosphoric acid also made the bitumens stiffer at lower 
temperatures but to a smaller extent. Adding of commercial waxes also in some cases resulted in stiffening effects at temperatures lower than $+5^{\circ} \mathrm{C}$. For the non-waxy bitumen NV, only adding FT-paraffin showed an increasing effect on the complex modulus at low temperatures.

Effects at lower temperatures may also be illustrated by comparing effects on the glass transition temperature, $T_{\mathrm{g}}$, at peak loss modulus and maximum rate complex modulus. Not for any binder mixture containing FT-paraffin, montan wax, polyethylene wax or polyphosphoric acid was the effect of adding the additive more than $\pm 2{ }^{\circ} \mathrm{C}$ on $\mathrm{T}_{\mathrm{g}}$ by DMA. Adding slack wax decreased $\mathrm{T}_{\mathrm{g}}$ by 2 to $6^{\circ} \mathrm{C}$. Also in the case of $\mathrm{T}_{\mathrm{g}}$ by DSC, the effect from adding commercial was in no case more than $\pm 2^{\circ} \mathrm{C}$.

In force ductility testing at $5^{\circ} \mathrm{C}$, maximum force load was considerably increased by the addition of FT-paraffin or montan wax, but not by polyethylene wax or polyphosphoric acid. The highest value of maximum load was shown for the binder mixtures containing both natural bitumen wax and FT-paraffin wax. Consequently, adding FT-paraffin or montan wax made bitumen stiffer and less cohesive or ductile at $+5^{\circ} \mathrm{C}$, while adding polyethylene wax or polyphosphoric acid showed marginal effects. Adding slack wax (Paper VIII) to the non-waxy bitumen NB made force ductility increase to some extent. The influence at lower temperatures of adding wax or polyphosphoric acid to waxy bitumen ME is illustrated in Figure 7, showing similar indications at $+5^{\circ} \mathrm{C}$.

It could be mentioned that a fracture or fracture toughness test, such as the low-temperature fracture test using BBR and sample bars with a starter notch, as suggested by Iliuta et al. (2004), could be a method better suited for measuring binder ability to withstand internal stresses leading to cracking. The reason suggested for this by Iliuta et al. was that the BBR fracture test is more directly related to the energy release during crack propagation compared to tests that measure strength, strain-to-failure, or ductility. Using the BBR fracture test method, addition of for instance $6 \%$ stabilized polyethylene has been shown to increase the fracture toughness at $-20^{\circ} \mathrm{C}$ by $50 \%$, although the binder stiffness was not greatly increased (Lee et al., 1994). However, it is important to note that the polyethylene wax used in the studies of this thesis is not of the same type as the one used in the study by Lee et al. In studies of this thesis (Papers VII and VIII), no correlation was found between BBR stiffness at $-25^{\circ} \mathrm{C}$ and TSRST fracture temperature (cf. Section4.2.1). 
In Paper III, it was found that effects due to natural wax or slack wax content in bitumen shown in DMA temperature sweeps were well related to the corresponding effects shown in DSC thermograms. In Paper V, this proved to be true as well for FT-paraffin, montan wax and polyethylene wax in bitumen, but not for polyphosphoric acid, showing no effects by DSC.
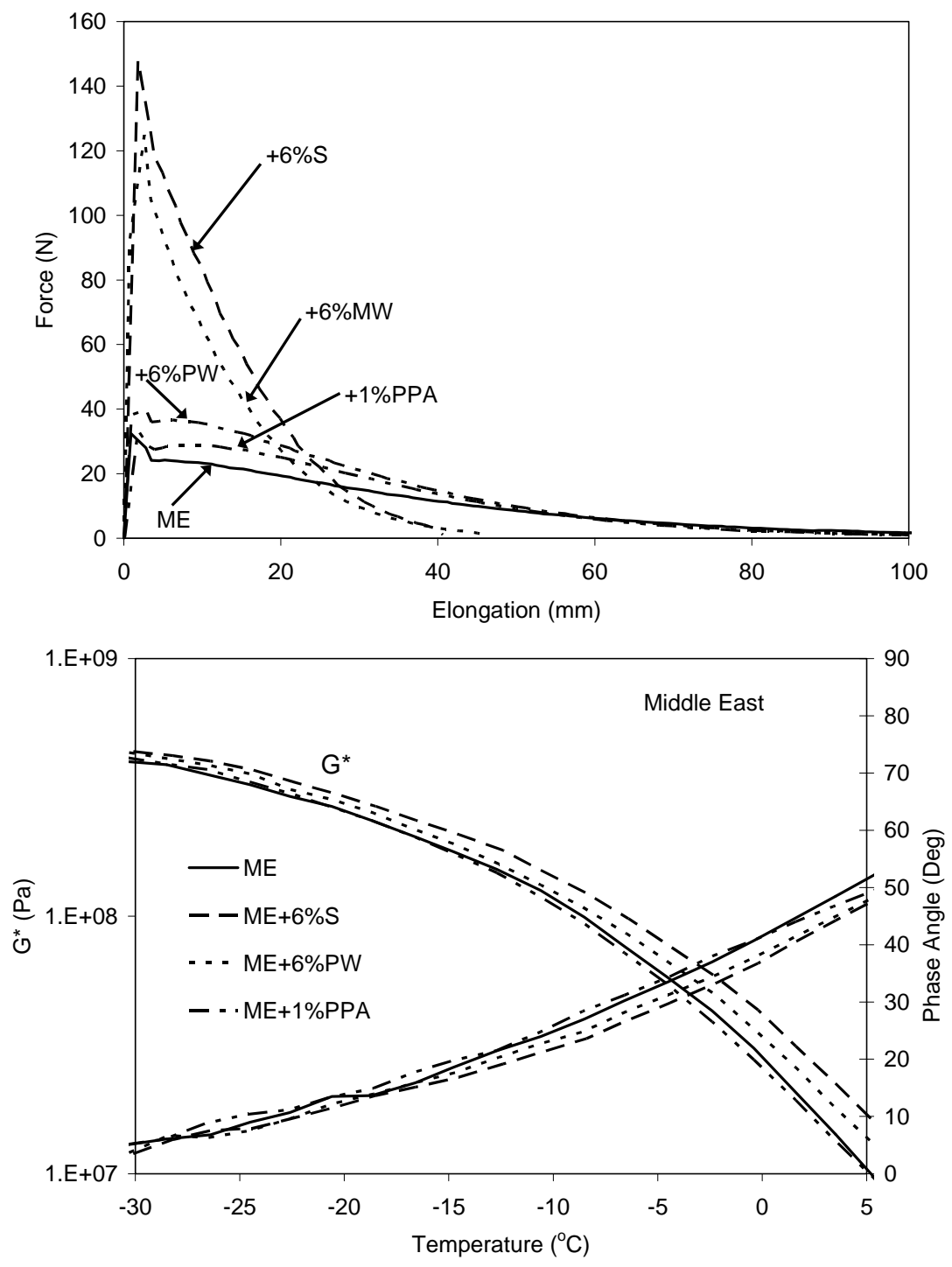

Figure 7. Force ductility curves at $+5^{\circ} \mathrm{C}$, and DMA at temperatures below $5^{\circ} \mathrm{C}$ for non-aged waxy bitumen $\mathrm{ME}$ mixtures. For sake of clarity, the $M E+6$ $\% M W$ graph is omitted in the lower figure diagram (Paper V). 


\subsubsection{Effects on irreversible ageing properties (Papers IV, V and VI)}

Generally speaking, bitumen is affected by atmospheric oxygen, UV light, and temperature changes, thereby becoming harder (decrease in penetration and increase in softening point). A great number of additives, such as hydrated lime and various types of anti-oxidants have been proposed as bitumen inhibitors. However, bitumen ageing is a very complex process and a determining factor influencing the degradation of asphalt pavements, and it is doubtful if any of these additives could be useful (Johansson 1998). Ageing occurs during mixing and laying (short term ageing) as well as during service life of the pavement (long term ageing). The main process of bitumen ageing is slow oxidation due to reaction with atmospheric oxygen. Other processes for bitumen ageing are evaporation of volatiles, physical hardening and exudation (slow migration of oil components). Short term ageing mainly is related to oxidation and evaporation, while long term ageing is related to oxidation and physical hardening. Physical hardening as a phenomenon is complex and not fully understood. Alteration of the molecular configuration, crystallization and collapse in free volume has been suggested as possible mechanisms. As physical hardening is not related to compositional changes, it is a reversible process. However sometimes physical hardening is causing major changes in rheological properties of bitumen. Low temperature physical hardening is dealt with in the next section (4.1.6).

Short and long term ageing often are simulated in the laboratory using different kinds of equipment, trying to accelerate the ageing processes. In the performed studies of this thesis, RTFOT and PAV standard methods and procedures were used. Irreversible ageing of bituminous binders leads to changes in chemical composition, influencing the rheological properties. The influence of adding FT-paraffin, montan wax or polyethylene wax on bitumen ageing properties were evaluated using DMA, BBR, force ductility test and chemical characterization by FTIR and TLC-FID.

Ageing increased the complex modulus of all mixtures (containing up to $6 \%$ wax additive), and elasticity was increased in the temperature range from 10 to about $50^{\circ} \mathrm{C}$, indicated by a decrease in phase angle. For the binder mixtures containing polyethylene wax and originally showing a large decrease in phase angle at higher temperature $\left(50-90^{\circ} \mathrm{C}\right)$, this decrease was markedly reduced by ageing indicating network damage. This is illustrated for waxy bitumen ME and non-waxy bitumen NV in Figures 8 and 9. 

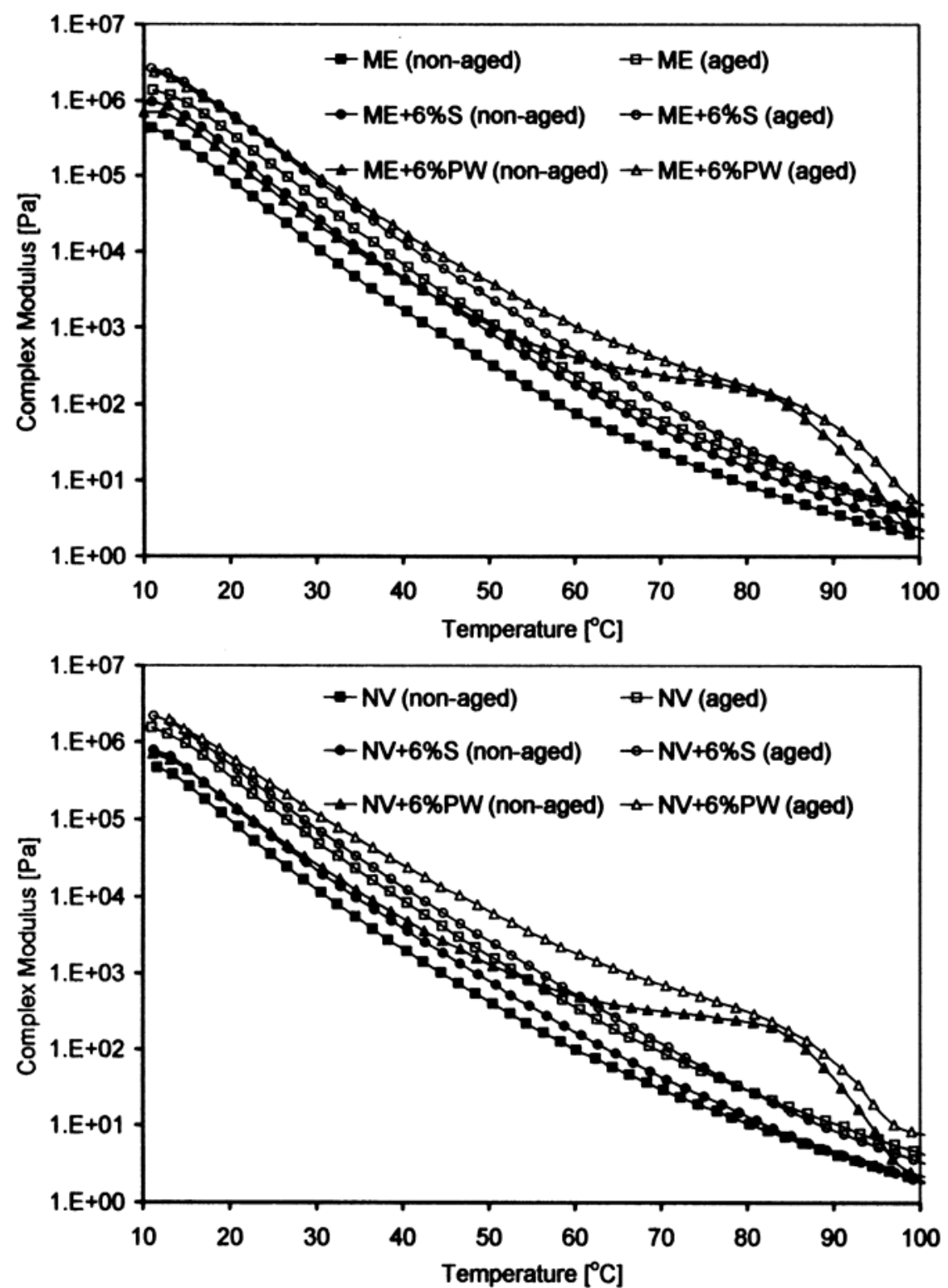

Figure 8. Complex modulus at $1 \mathrm{rad} / \mathrm{s}$ as a function of temperature for base and wax modified bitumens $M E$ and $N V$ before and after ageing (RTFOT + $P A V)$ (Paper VI). 

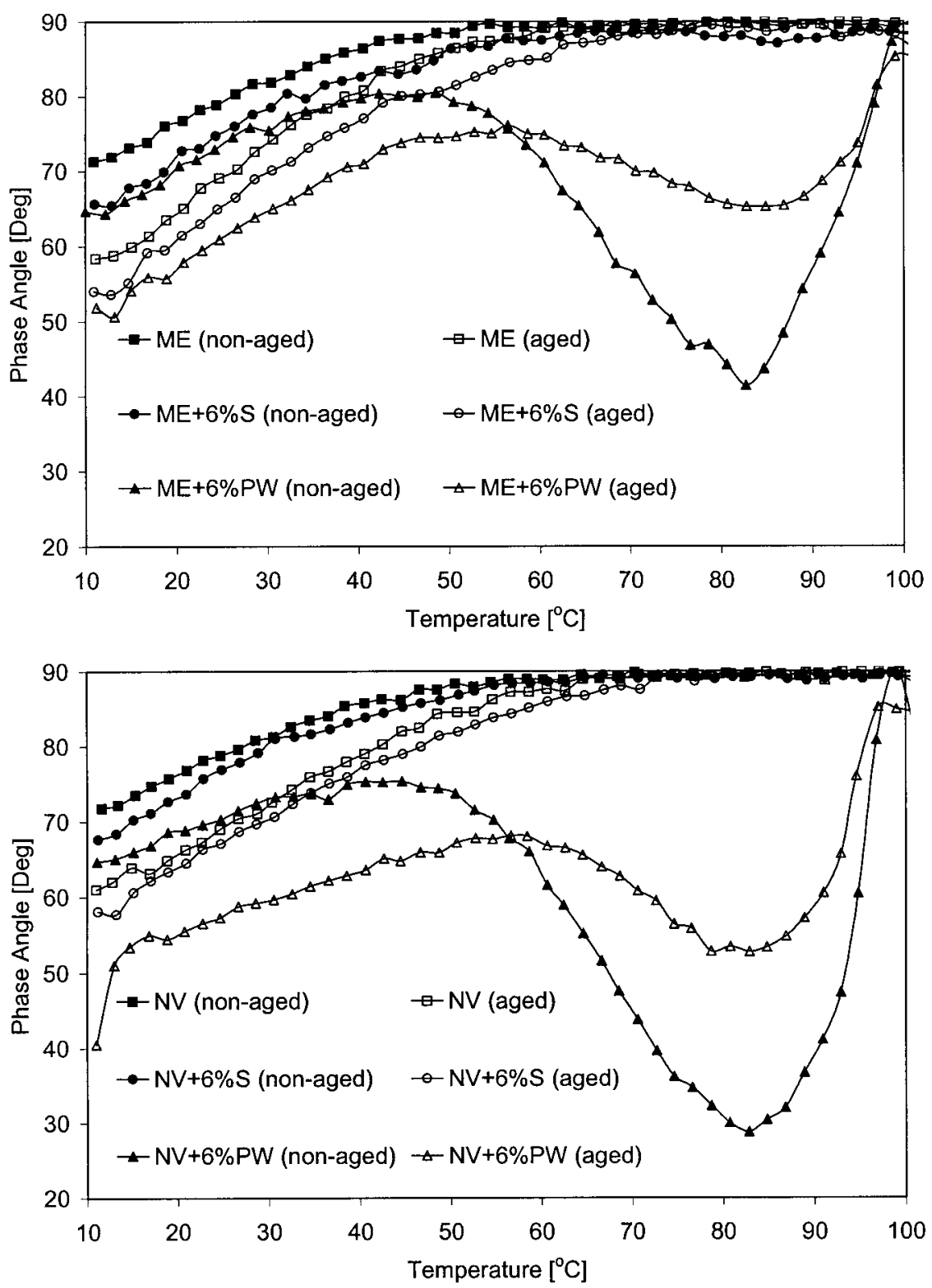

Figure 9. Phase angle at $1 \mathrm{rad} / \mathrm{s}$ as a function of temperature for base and wax modified bitumens $M E$ and NV before and after ageing (RTFOT + $P A V)$ (Paper VI). 
Ageing increased force ductility loads at $+5^{\circ} \mathrm{C}$ for all binder mixtures containing FT-paraffin, montan wax or polyethylene wax, but the degree of ageing was not increased by the addition of wax. Also for BBR stiffness at $-25^{\circ} \mathrm{C}$, the degree of ageing was not increased by the addition of wax.

Oxidation may be measured by functional group analysis using infrared spectroscopy. The main chemical change due to oxidation is the formation of carbonyls and sulphoxides. Adding FT-paraffin, montan wax or polyethylene wax did not increase the IR sulfoxide absorbance at $1030 \mathrm{~cm}^{-1}$ for any of the aged (or non-aged) binders tested. Carbonyl absorbance at $1705 \mathrm{~cm}^{-1}$ was decreased for base bitumen ME and WB, due to the addition of wax, but increased for non-waxy base bitumen NV. Comparing ratios of carbonyl absorbance of the aged to non-aged binder, bitumen NV showed higher resistance to ageing than bitumen ME and a decrease in ageing index due to the addition of wax.

Statistic analysis of variance was performed using a general linear model (GLM) procedure on the IR absorbance results (for NV and ME mixtures) using Statistical Package for the Social Sciences (SPSS). Models were established for carbonyl compounds, sulfoxides and ageing index and significances of factors (independent variables) were determined. Type III hypothesis test was used at a significance level of 0.05 . (Type III mean squares indicate the influence of that factor, after the effects of all other factors in the model have been removed. If the Type III $\mathrm{Pr}>\mathrm{F}$ value of a factor is less than 0.05 , the factor is considered to be significant.) Furthermore, Fisher's least square difference (LSD) and Tukey's HSD tests (multiple comparison tests) were applied to determine the significances of levels of each factor. These statistical results were considered in the process of formulating results and discussions for the FTIR analysis in Paper VI.

The TLC-FID technique was used for determining changes in generic composition of bitumens during ageing. In this study (Paper VI), the wax additives mainly formed part of the asphaltene generic phase as determined by TLC-FID. The colloidal index, expressed as

$$
C I=\frac{\text { (aromatics }+ \text { resins })}{\text { (saturates }+ \text { asphaltenes })}
$$

was decreased by the addition of wax, more for aged than for non-aged samples, possibly indicating a stronger bitumen network structure after ageing due to the addition of wax. 
In conclusion, addition of the commercial waxes used (FT-paraffin, montan wax and polyethylene wax) showed no or marginally positive influence on bitumen ageing properties for the bitumens, temperatures and frequencies used.

\subsubsection{Effects on low temperature physical hardening}

As mentioned in the previous section, physical hardening is a reversible process, sometimes causing major changes in rheological behaviour of bitumens (without altering its chemical composition).

Physical (steric) hardening at intermediate temperatures is due to molecular structuring and self-assembly of polar molecules, striving towards a state of energetic minimum and resulting in isothermal stiffening of the binder. The process is comparably slow and may continue for a long time.

Low temperature physical hardening may occur below as well as above the glass transition temperature, $\mathrm{T}_{\mathrm{g}}$, making the bitumen stiffer and more elastic. Crystallization of waxes and free volume collapse has been suggested as possible mechanisms (Anderson et al., 1999). However, physical hardening and the effect of waxes on physical hardening of bitumens are still not fully understood.

In Papers $\mathrm{V}$ and VIII, physical hardening after $24 \mathrm{~h}$ at $-25^{\circ} \mathrm{C}$ was determined using the BBR. The effect was expressed by a physical hardening index, PHI, simply defined as the stiffness ratio between stiffness values after $24 \mathrm{~h}$ and $1 \mathrm{~h}$ storage time, respectively, at this temperature. Comparing the three base bitumens used in Paper V, the two bitumens containing natural bitumen wax showed significant higher hardening index than the non-waxy bitumen (53 and $49 \%$, respectively, compared to $8 \%$ ). Adding FT-paraffin to the two waxy base bitumens decreased the hardening index to some extent (see Figure 10). Also montan wax and polyethylene wax showed this influence. The effect (decrease in PHI) increased with increased content of additive. The opposite effect (increase in PHI) was gained when adding polyphosphoric acid (to waxy bitumen ME). For the non-waxy bitumen, the effects were much smaller and did not necessarily depend on additive content. Adding $6 \%$ montan wax to the non-waxy bitumen gave the largest increase in physical hardening index for this bitumen (although far below the values of the two bitumens containing natural bitumen wax). Also for the non-waxy bitumen NB (used in Paper VIII), the comparably high PHI (30\%) was decreased by the addition of 
FT-paraffin or polyethylene wax but not by montan wax or polyphosphoric acid. Adding slack wax made physical hardening increase by almost $100 \%$ (cf. Paper VIII).

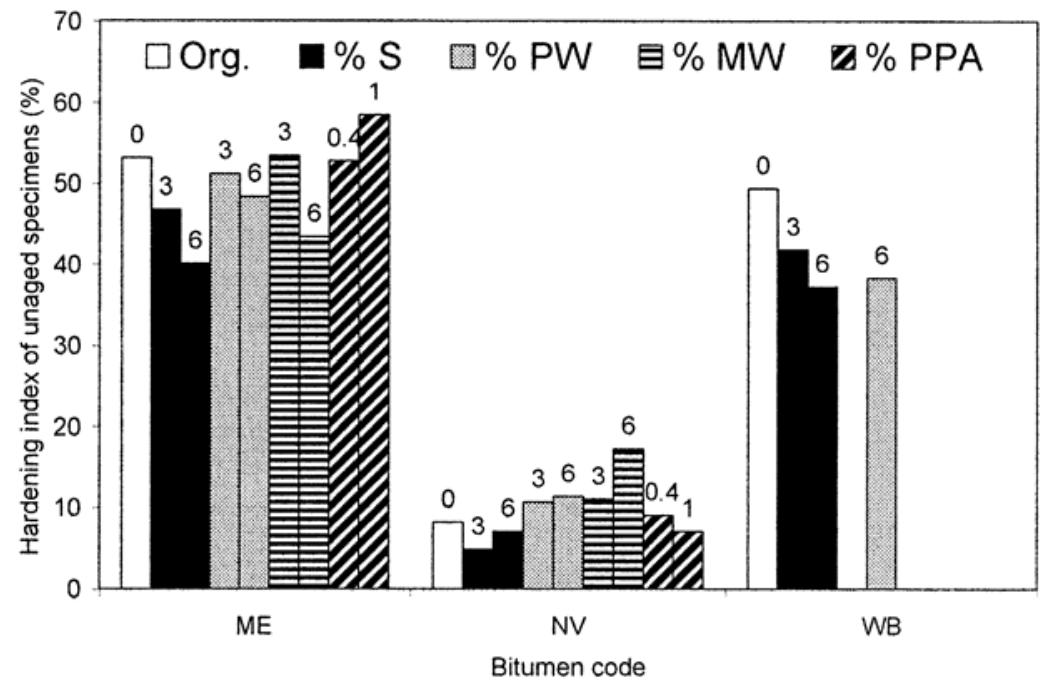

Figure 10. Effect on physical hardening index PHI due to addition of commercial wax or PPA (Paper V).

No correlation between physical hardening index (PHI) and wax content by DSC was found in this study, involving both natural bitumen wax and commercial wax, and the PHI for the bitumens studied was not markedly affected by the wax additives.

Enthalpy change by DSC was not found to be a good indicator of physical hardening. For instance, the bitumen containing $3.8 \%$ crystallizing fraction by DSC (natural bitumen wax) showed a physical hardening at $-25^{\circ} \mathrm{C}$ of $53 \%$, while the non-waxy bitumen containing $6 \%$ added FT-paraffin ( $10.5 \%$ crystallizing fraction by DSC) showed only $7 \%$. 


\subsection{Asphalt concrete mixtures (Papers VII - VIII)}

For the first asphalt concrete study (Paper VII), the binder mixtures were selected from the earlier performed binder studies on rheology and ageing. Since comparably limited amounts of these base bitumens were available, only five asphalt concrete mixtures could be prepared and tested. For these asphalt mixtures, base bitumens NV, ME and WB were used containing no or $6 \%$ by weight of FT-paraffin or polyethylene wax. For base bitumens $\mathrm{ME}$ and $\mathrm{WB}$, respectively, only one mixture containing $6 \%$ of polyethylene wax was prepared. For base bitumen NV, mixtures containing no wax, $6 \%$ FT-paraffin and $6 \%$ polyethylene wax, respectively, were prepared. Consequently, the influence of natural bitumen wax on asphalt concrete performance could hardly be judged from the results of this study. Effects on low and medium temperature performance were investigated using TSRST, dynamic creep and complex modulus tests (cf. Section3.5).

For the second asphalt concrete study (Paper VIII), a non-waxy bitumen of penetration grade 160/220 was modified with FT-paraffin, montan wax, polyethylene wax, slack wax and polyphosphoric acid, respectively, at two content levels ( 3 and $6 \%$ ) and used in the asphalt mixtures. This base bitumen was taken from the bitumen depot in Södertälje early in 2005 . Mainly the same investigations as in Paper VII were performed, adding a creep test at $-25^{\circ} \mathrm{C}$ for two of the asphalt mixtures.

\subsubsection{Influence of additive on medium temperature performance}

Properties at medium temperatures $\left(0-40^{\circ} \mathrm{C}\right)$ were investigated by the use of dynamic creep and complex modulus tests.

\section{Dynamic creep test at $40^{\circ} \mathrm{C}$}

The smallest strains, indicating better resistance to permanent deformation, were shown for the mixtures containing FT-paraffin or montan wax. As expected, adding $6 \%$ of slack wax (Paper VIII) made the asphalt concrete extremely sensitive to rutting; in fact the specimens were destroyed during testing. Adding polyethylene wax in some cases showed no or smaller positive effects (Paper VII), while in other cases (Paper VIII) significant improvement. The reason for this behaviour could be that the polyethylene used is comparably sensitive to ageing, which was shown in binder testing (Paper VI). There could also be some instability problems. Adding $6 \%$ of polyethylene to the non-waxy bitumen NV (Paper VII) showed no 
significant effect on the resistance to deformation in dynamic creep testing at $40^{\circ} \mathrm{C}$, while adding the same amount to the non waxy bitumen NB (Paper VIII) made the resistance increase by approximately $40 \%$. Adding PPA ( $1 \%$ ) increased the sensitivity to rutting to some extent for bitumen NB. Results from dynamic creep testing reported in Paper VIII are shown in Figure 11.

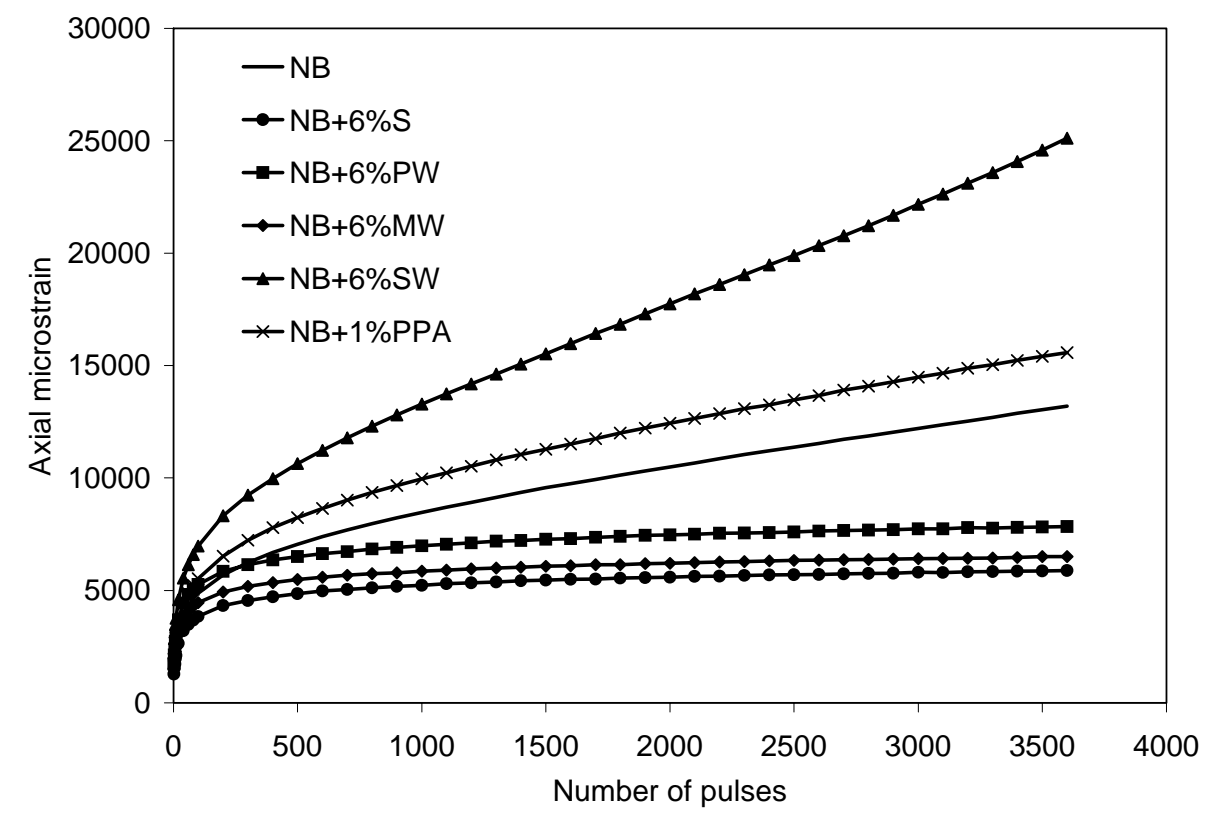

Figure 11. Effect on axial deformation in dynamic creep testing $\left(40^{\circ} \mathrm{C}\right)$ due to the addition of $6 \%$ commercial wax or $1 \%$ polyphosphoric acid to nonwaxy bitumen NB (Paper VIII).

By comparing the results from dynamic creep testing of asphalt mixtures at $40^{\circ} \mathrm{C}$ with the corresponding binder test results from DMA analysis, that is complex modulus or rutting factor $\left(\mathrm{G}^{*} / \sin \delta\right)$ at $40^{\circ} \mathrm{C}$ or $60^{\circ} \mathrm{C}$, one would expect a larger effect from the addition of polyethylene wax and polyphosphoric acid, which showed the highest values in binder testing (cf. Figure 5, lower diagram). Quite contrary to this, adding polyphosphoric acid made the asphalt concrete more sensitive to permanent deformation (cf. Figures 11 and 12). 


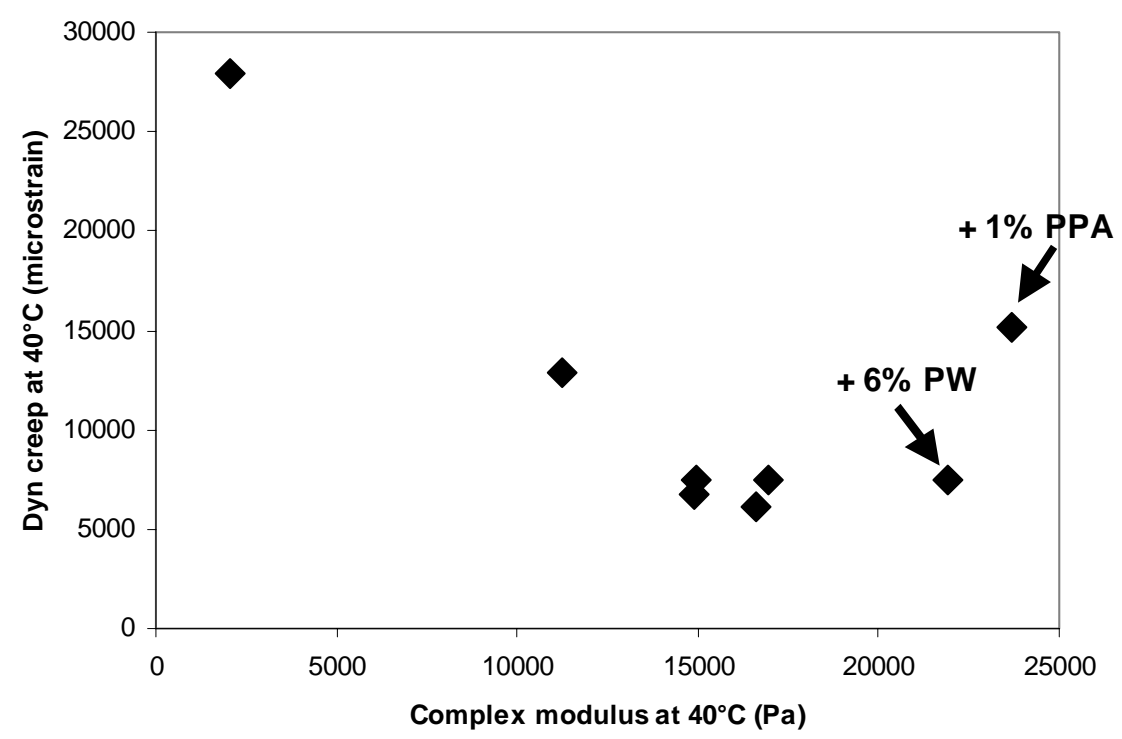

Figure 12. Correlation between dynamic creep at $40^{\circ} \mathrm{C}$ (permanent deformation after 3600 pulses) for the asphalt concrete mixture and complex modulus at the same temperature for the binder used in the mixture.

\section{Complex modulus test}

Adding FT-paraffin or polyethylene wax to non-waxy bitumen NV (Paper VII), clearly increased the modulus and decreased the phase angle within the specific temperature range used (from 0 to $20^{\circ} \mathrm{C}$ ).

The corresponding influence on non-waxy bitumen NB is illustrated in Figure 13, showing also evident stiffening effect at lower frequencies due to the addition of slack wax, but minor or no influence from adding polyphosphoric acid.

Time-temperature superposition (replaceability between temperature and time for so-called thermo-rheologically simple materials) may not be strictly applicable, especially not to the binder mixture containing $6 \%$ slack wax. Nevertheless, at least for the dynamic modulus, isotherms could be reasonably well shifted to form a continuous master curve. 

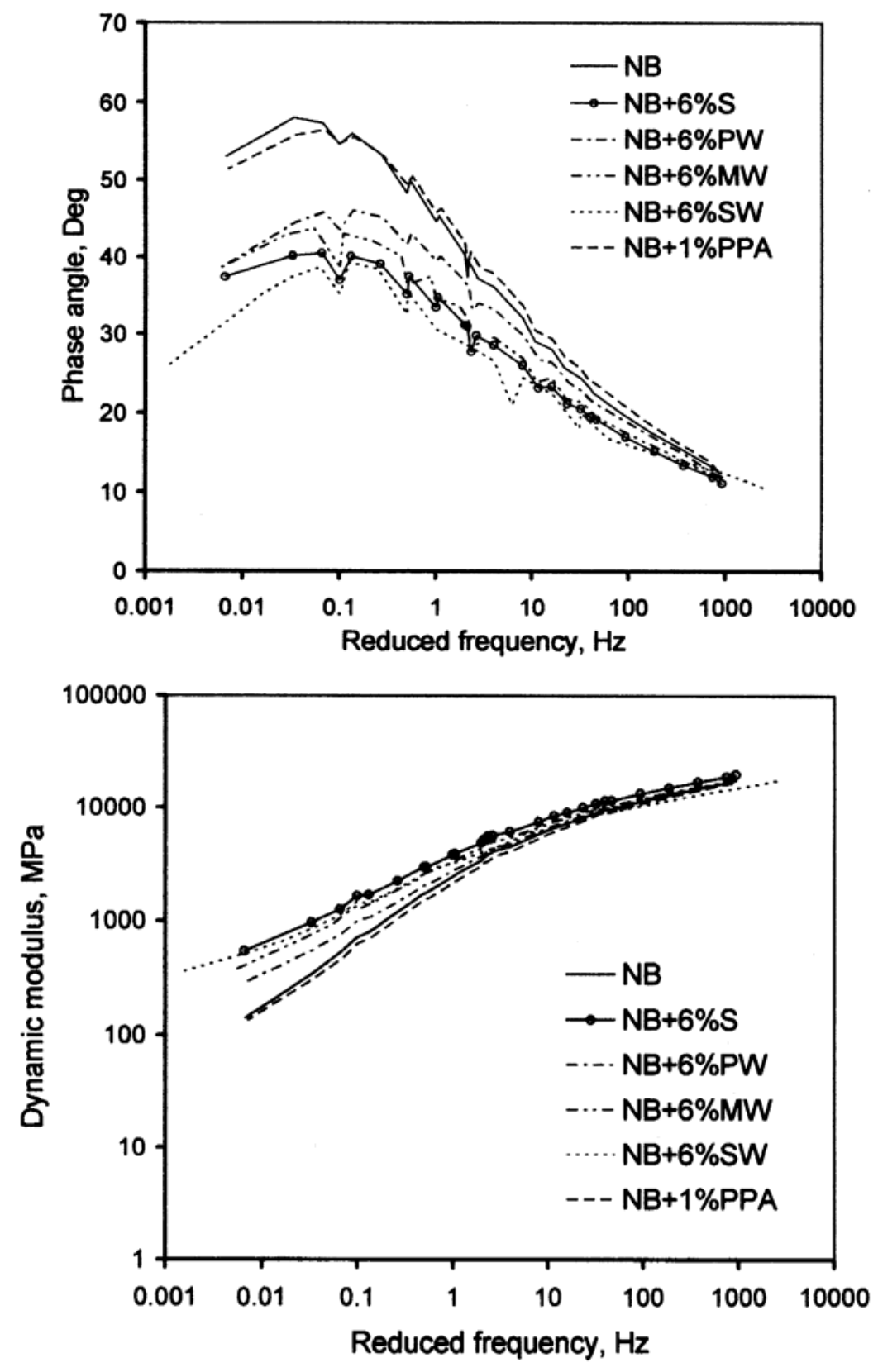

Figure 13. Dynamic modulus and phase angle master curves for the NB and modified NB asphalt mixtures. The reference temperature is $10^{\circ} \mathrm{C}$ (Paper VIII). 


\subsubsection{Influence of additive on low temperature performance}

Low temperature properties of asphalt mixtures were investigated by the use of TSRST and creep testing at $-25^{\circ} \mathrm{C}$.

\section{TSRST}

The TSRST fracture temperature for the non-waxy bitumens NV (Paper VII) and NB (Paper VIII) was somewhat increased (by about $2^{\circ} \mathrm{C}$ ) from the addition of FT-paraffin or montan wax, but unchanged from the addition of polyethylene wax or slack wax. Adding $1 \%$ of polyphosphoric acid made the fracture temperature decrease by about $2^{\circ} \mathrm{C}$. Ageing $\left(42\right.$ days at $\left.85^{\circ} \mathrm{C}\right)$ made the TSRST temperature increase by 1 to $5^{\circ} \mathrm{C}$. Fracture temperature was significantly influenced by binder type and ageing. Examples of test results from the TSRST are illustrated in Figure 14.

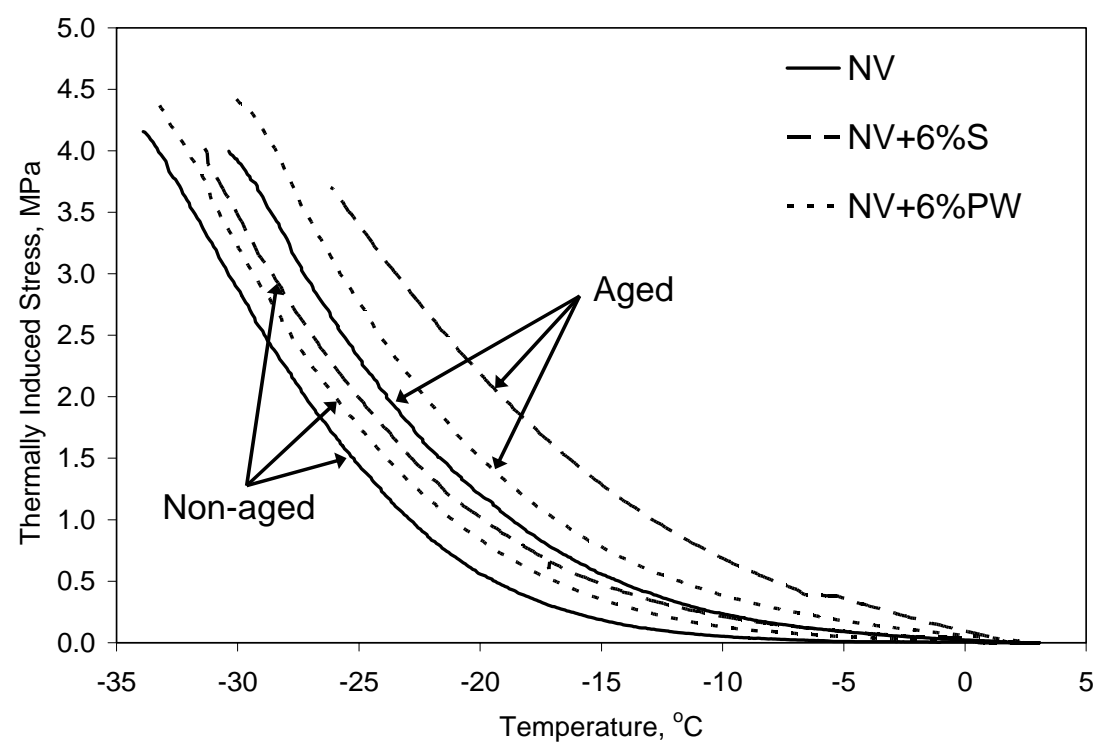

Figure 14. TSRST response for asphalt concrete containing bitumen $N V$ or wax modified $N V$ binder mixtures, before and after ageing (42 days at $85^{\circ} \mathrm{C}$ ) (Paper VII).

Statistical analysis was performed (Paper VII) for evaluating the influence of variables on fracture temperature and fracture stress at a 0.05 significance level using a Statistical Package for Social Sciences (SPSS). The analysis of covariance (ANCOVA) was performed using a general linear model (GLM) 
procedure. The variables considered were binder type (5 types), ageing at two levels (non-aged and aged 42 days at $85^{\circ} \mathrm{C}$ ) and air voids content. Since air voids content was not fully controlled, it was taken as covariate. The data set included totally 28 test results. Fracture temperature was found significantly influenced by binder type and ageing, but not by air void content, while fracture stress was significantly influenced only by air void content. Least-square means (LSMEAN) of the test results were obtained as well, using the GLM procedure. LSMEAN are mean values of test results adjusted for an average value of air voids content. The ranking of low temperature cracking resistance of binders based on TSRST fracture temperature of the asphalt concrete mixtures tested was found to be:

$\mathrm{NV}>\mathrm{NV}+6 \% \mathrm{PW}>\mathrm{ME}+6 \% \mathrm{PW}>\mathrm{WB}+6 \% \mathrm{PW}>\mathrm{NV}+6 \% \mathrm{~S}$.

In Paper VII, physical hardening at $-25^{\circ} \mathrm{C}$ was investigated by comparing specimens submitted to unstrained cooling for $24 \mathrm{~h}$, followed by TSRST, to specimens following the standard test procedure. Due to the lower starting temperature for stored specimens, no increase in fracture temperature could be observed, although significant physical hardening (of about $50 \%$ ) was observed by BBR for some of the binders used in the mixtures. As already mentioned, these binders were the two base bitumens already containing natural bitumen wax, and the hardening index was not further increased by the addition of commercial wax. The non-waxy bitumens showed less physical hardening (about $10 \%$ and $30 \%$, respectively, for base bitumens $\mathrm{NV}$ and NB). Especially, adding slack wax increased the PHI (from 30 to about $55 \%$ for bitumen NB).

In Paper VIII, physical hardening using TSRST was investigated by comparing stored specimens $\left(24 \mathrm{~h}\right.$ at $\left.-25^{\circ} \mathrm{C}\right)$ to specimens conditioned for $3 \mathrm{~h}$ at $-25^{\circ} \mathrm{C}$, starting the test at that temperature. The difference between fracture temperatures after $3 \mathrm{~h}$ compared to $24 \mathrm{~h}$ was found to be between -0.75 and 1.75 , indicating no or minor effects due to the longer storage time used.

\section{Creep testing}

In Paper VIII, creep testing was performed at $-25^{\circ} \mathrm{C}$ for the asphalt mixtures containing base bitumen NB, without modification, or modified with $6 \%$ slack wax. Creep testing was performed after 3, 7, 11, 15, 19 and $23 \mathrm{~h}$ of storage at $-25^{\circ} \mathrm{C}$. The results show an increase in stiffness of the asphalt mixtures, increasing with loading time. The relative change in compliance 
after $23 \mathrm{~h}$ of storage and stress applied for $240 \mathrm{~s}$ was $16 \%$ for the mixture containing slack wax compared to $11 \%$ for the mixture containing solely base bitumen NB. Creep testing curves (compliance) for the mixture containing slack wax is shown in Figure 15.

Comparing these results to the corresponding results of low temperature physical hardening for the binders using BBR, the effect on asphalt concrete is less pronounced.

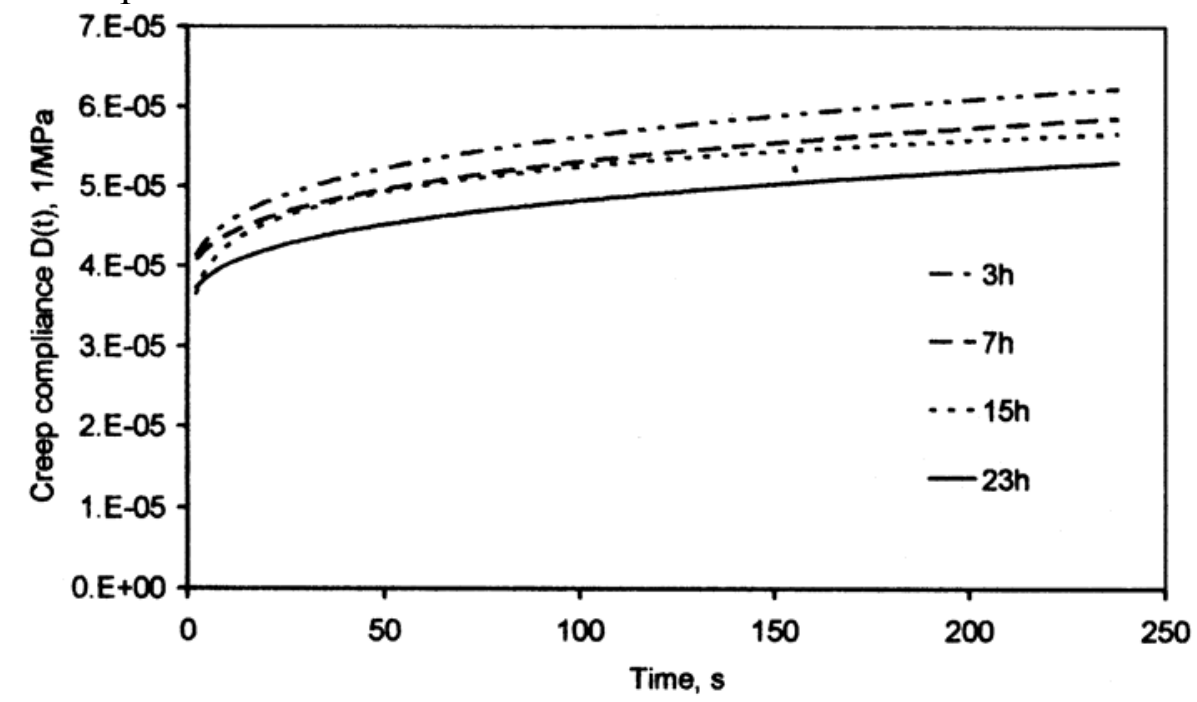

Figure 15. Creep test at $-25^{\circ} \mathrm{C}$ for asphalt concrete containing bitumen NB and 6\% slack wax. Compliance increase (stiffness decrease) with loading time and decrease with storage time (Paper VIII).

\section{Discussions}

The influence of natural wax in bitumen and asphalt concrete has been under discussion for decades, implying negative as well as positive effects. However, natural wax in straight run bitumen today normally is low in content and of a kind not likely to be harmful to binder or asphalt concrete properties. The main reason is that bitumen waxes contain no or very little $n$-alkanes due to the production process normally used in refineries. This gradually became clear from the literature review and earliest performed studies within this project and other recently performed studies. Great efforts were made in trying to find bitumen containing harmful natural wax for use in this project. However, the efforts were unsuccessful. From this 
point of view, the use of commercial waxes as additive to bitumen, in order to gain certain positive effects, became of increased interest in the project. Furthermore, it was found that addition of commercial waxes was quite widely used not only as flow improvers but also for gaining stiffening effects similar to those of polymer modification.

In general, effects of natural wax in bitumen depend on several factors such as chemical composition of the bitumen and especially the type of wax. Crystallizing material with no or very low $n$-alkane content gives no negative complex modulus lowering effect at higher temperatures, indicating lower resistance to plastic deformation. However, stiffening effects may occur down to very low temperatures. One bitumen property that could be influenced by natural wax is low temperature physical hardening. To what extent this would also affect asphalt concrete properties is not well known. Additionally, asphalt concrete mixtures containing natural bitumen wax may also show lower resistance to low temperature cracking.

Natural wax content in bitumen obtained by DSC gives a relative amount of material taking part in the total phase transition over the entire test temperature range used in the test. Effects shown in such thermograms for bitumen containing wax were found to be well related to the corresponding effects shown in DMA temperature sweeps. Additionally, DSC thermograms may give some indications on type of natural wax and possible rheological effects due to crystallization and melting of the wax in the bitumen.

Specific heat (the amount of heat needed to raise the temperature of one gram of a substance by $1{ }^{\circ} \mathrm{C}$ ) and fusion heat (enthalpy) are important thermal properties to be considered in calculating wax content in bitumen by DSC. For DSC-analysis of natural wax in bitumen, $121.3 \mathrm{~kJ} / \mathrm{kg}$ has been used as reference enthalpy in calculations. This figure is an estimated average value developed by Nynas in the 1980's for natural wax in bitumen. However, different types of wax and binders show different melting enthalpies. The enthalpy value of a certain wax in bitumen is dependent on the bitumen and differs from the value of the pure wax. It varies considerably for different $n$-alkanes or other types of wax, and consequently also for different mixtures of wax in bitumen, probably making DSC less reliable as a method for determining wax content (crystallizing fraction) in bitumen. Microcrystalline paraffin waxes show lower fusion heat than 
macrocrystalline waxes depending on the lack of or fewer solid phase transitions. Enthalpy values used for different waxes vary between approximately 145 and $250 \mathrm{~kJ} / \mathrm{kg}$ (Mózes 1982, Létoffé et al. 1995, Brulé et al., 1990). For the FT-paraffin and montan wax used in this study, higher enthalpy values than $121 \mathrm{~kJ} / \mathrm{kg}$ would have been more suitable. Considering that this estimated average value for natural wax in bitumen is about 25 years old, it may not be representative for the bitumens produced today. Considering also the fact that bitumens nowadays may be modified with different types of commercial wax, complementary methods are needed if wax content (at all) is to be determined.

The influence of commercial flow improving waxes like FT-paraffin or montan wax has not been discussed as long as natural wax, although early examples could be found (Abraham 1954), where the addition of wax (ozocerite, montan wax or synthetic wax) in bitumen is mentioned as desirable, such as for reducing stickiness. The main purpose of such an addition nowadays is to reduce the mixing temperature of the asphalt in order to reduce also energy consumption and emissions, but also to improve workability and handling. Furthermore, lower void content due to improved compaction should make the pavement more dense and durable. Additional positive effects, such as improved resistance to deformation at higher temperatures for asphalt concrete have been reported as well. However, in the case of using flow improvers in combination with polymer modified binders and asphalt mixtures, the mixture may simply be too dense and elastic causing blistering problems under certain circumstances. This has been reported for pavements on Swedish airfields.

\subsection{Experimental}

Two of the base bitumens used in the experiments of this study, NV and $\mathrm{NB}$, respectively, were both non-waxy, that is no crystallizing fraction by DSC was obtained. However, the influence on binder properties by the addition of the different types of waxes varied. For instance, bitumen NV was more affected at higher temperatures by FT-paraffin and polyethylene wax than bitumen NB (cf. Figures 4 and 5), while bitumen NB was more effected by slack wax, and showed higher $\mathrm{CF}$ (crystallizing fraction) values by DSC from the addition of wax. Adding $6 \%$ of slack wax or montan wax to NB gave a $\mathrm{CF}$ value of $8 \%$ (Paper VIII), while adding $6 \%$ of slack wax to bitumen NV gave only $4 \%$ (Paper III). This might partly be explained by assuming that some parts of the waxes were dissolved in bitumen $\mathrm{NV}$ but 
not in bitumen NB due to differences in chemical structure. Such chemical differences detected in the studies were higher CI (colloidal index) by TLCFID for bitumen NV, and more carbonyl compounds by IR spectroscopy, possibly indicating lower colloidal stability and higher polarity. Other differences between the non-waxy binders were lower viscosity for NB, lower acid number (2.8 compared to 3.6 for NV) and higher PHI (30\% compared to $8 \%$ for NV). The melting point of macrocrystalline waxes like slack wax is known to drop $\left(20-30^{\circ} \mathrm{C}\right)$ when added to bitumen as a result of mixing effects. For bitumen, NB this drop was obviously larger than for NV. However and as already mentioned (cf. Section 3.1), the slack wax used in Paper III and VIII, respectively, was not one and the same product and therefore may differ, not only slightly in congealing point, but also in viscosity and oil content.

As mentioned earlier, adding FT-paraffin or montan wax to bitumen, has been performed in practice mainly for the purpose of reducing the asphalt mixture temperature and thereby also energy consumption and emissions. Depending on a number of factors, other properties may be more or less affected as well. Adding up to $6 \%$ of the FT-paraffin or montan wax products used in this study to waxy or non-waxy bitumens of penetration grade 160/220 showed noticeable stiffening effects at temperatures from about $+100^{\circ} \mathrm{C}$ down to at least $+5^{\circ} \mathrm{C}$. As a rule, the effect from adding FTparaffin was larger than from adding montan wax. However, these waxes showed the highest stiffening effects in terms of softening point, penetration and force ductility but not in DMA. In asphalt concrete testing at medium temperatures (dynamic creep at $40^{\circ} \mathrm{C}$ and complex modulus between 0 and $20^{\circ} \mathrm{C}$ ), the mixtures containing non-waxy bitumen and FT-paraffin or montan wax showed the smallest strains (indicating better resistance to rutting) as well as highest modulus. In most cases, stiffening effects were shown also at temperatures down to $-25^{\circ} \mathrm{C}$ using DSR and BBR for binder mixtures containing FT-paraffin or montan wax (in most cases). Also in TSRST testing of mixtures, the fracture temperature was increased by about $2{ }^{\circ} \mathrm{C}$ due to the addition of these additives. Adding FT-paraffin or montan wax to the two waxy base bitumens decreased their high physical hardening indexes to some extent, but this was not necessarily so for the non-waxy bitumens.

The polyethylene wax product used in this study is normally not used as modifier in bitumen or asphalt mixtures in practice. Nevertheless, it was selected for the project as a possible and interesting alternative. Adding 
polyethylene wax showed a considerable stiffening effect by DMA from about +25 to $+90^{\circ} \mathrm{C}$. The reason for this is explained by its comparably narrow melting temperature range and ability (as a thermoplastic polymer) to associate with bitumen. Stiffening effects in terms of empirical characteristics were considerably lower than for FT-paraffin, but higher than for polyphosphoric acid. However, in asphalt concrete testing (dynamic creep and complex modulus), the stiffening effects were lower compared to the mixtures containing FT-paraffin. Low temperature binder performance was affected to a minor, or in some case even positive extent (decrease in PHI), by the addition of polyethylene wax. The fracture temperature by TSRST was unchanged from the addition of polyethylene wax.

Polyphosphoric acid is a bitumen modifier used for improving high and low temperature performance by acting as a deflocculant of the asphaltene bitumen fraction in neutralizing polar groups (Baumgardner et al., 2005). According to Orange et al. (2004), adding polyphosphoric acid may increase binder classification by one or two penetration grades, as well as give positive effects in combination with polymers. The improvement is suggested to be due to modification of the base bitumen through interactions between asphaltenes and polyphosphoric acid, affecting hydroxyl groups by the creation of phosphate ester functional groups on asphaltenes and acidbase reactions. Furthermore, polyphosphoric acid is reported to be temperature stable and non-oxidizing, but not to improve workability and handling conditions.

Adding polyphosphoric acid in the studies of this thesis showed a noticeable positive stiffening effect by DMA from about +25 to $+90^{\circ} \mathrm{C}$, but the stiffening effects in terms of empirical characteristics were lower than for the rest of the additives discussed above. Surprisingly, in asphalt concrete testing, adding polyphosphoric acid made the asphalt concrete more sensitive to permanent deformation. The reason for this could possibly be explained by further chemical interactions between additive, base bitumen, and aggregate, neutralizing the effect of the acid.

Adding polyphosphoric acid showed minor or positive effects on binder low temperature performance (lower stiffness in some cases), and also made the TSRST asphalt mixture fracture temperature decrease by about $2^{\circ} \mathrm{C}$ (for non-waxy bitumen NB). On the other hand, binder physical hardening was slightly increased in some cases by the addition of polyphosphoric acid. 
Summarizing, the effects of adding commercial wax or polyphosporic acid to bitumen in this study varied depending on bitumen and temperature range studied, but were mainly of positive or vague nature.

\section{Conclusions}

The most important conclusions drawn from the literature review are:

- Determination of wax content is not meaningful for specification purposes.

- Decisive for the effect of wax is the temperature range of application and the definition chosen for wax in bitumen.

- Natural wax in straight run bitumen today is low in content and of a type which should not be particularly harmful for binder or asphalt concrete properties. However, wax could unintentionally be produced through refining procedures like visbreaking or hydrocracking, affecting bitumen properties.

- The most feared influence of wax in bitumen is the sudden decrease in viscosity due to the melting of crystallized wax, if this should occur within a temperature range affecting the resistance to permanent deformation of binder and asphalt pavement.

- Results and experience concerning negative effects of wax in bitumen are based mainly on laboratory studies on bitumen and bitumen mixtures, and very few studies concerning effects of waxy bitumens on pavement properties have been reported.

- For blown bitumens and/or wax modified bitumens in road construction, the effects on asphalt concrete properties may vary considerably.

- During the last decade, commercial waxes have been widely used not only as flow improvers but also for gaining stiffening effects similar to those of polymer modification.

The most important conclusions drawn from the experimental studies of this thesis are:

- Magnitude and type of effect on bitumen rheology depend on the bitumen itself as well as type and amount of additive. Bitumen composition is of decisive importance. 
- None of the commercial additives (except slack wax, which is never used in practice as an additive to bitumen) showed any negative sudden complex modulus lowering effect at higher temperatures, thereby possibly affecting rutting resistance in a negative way.

- Adding polyethylene wax or polyphosphoric acid, especially to the nonwaxy bitumens used, showed considerable stiffening effects at medium and higher temperatures. However, the corresponding effects could not be shown in dynamic creep testing (at $40^{\circ} \mathrm{C}$ ) of asphalt concrete mixtures containing these modified binders.

- Physical hardening as determined by $\mathrm{BBR}$ at $-25^{\circ} \mathrm{C}$ showed a higher hardening index for the two bitumens containing natural wax than for the two non-waxy bitumens. Adding FT-paraffin decreased the hardening index for all bitumens. Also polyethylene wax and montan wax showed this effect, but not for all bitumens. Slack wax showed a large increasing effect on physical hardening, and polyphosphoric acid none or minor effect.

- No correlation between physical hardening index (PHI) and wax content by DSC was found in this study, involving both natural bitumen wax and commercial wax. Consequently, enthalpy change by DSC was not found to be a good indicator of physical hardening.

- Addition of the commercial waxes used (FT-paraffin, montan wax and polyethylene wax) showed no or marginally positive influence on bitumen ageing properties for the bitumens and test conditions used.

- Comparing asphalt mixture test results to the corresponding binder test results, the effects on asphalt mixtures from adding commercial wax or polyphosphoric acid were less evident.

- The recommendation of the author is to carefully evaluate in the laboratory the effects of adding any type of commercial additive to a specific bitumen intended for modification before using it in practice. 


\section{Acknowledgements}

I would like to express my thanks to Professor Ulf Isacsson for having employed me at the $\mathrm{KTH}$, initiated and supervised this $\mathrm{PhD}$ project and for giving valuable criticism to papers and thesis.

Thanks also go to Dr Yuksel Tasdemir for his passionate and skilful contribution in performing the main part of the laboratory experiments.

Jonas Ekblad is gratefully recognized for his excellent technical support and advice in the laboratory.

Some financial support by Nynas Bitumen AB and the Swedish Road Administration is gratefully acknowledged.

Nynas Bitumen AB is gratefully acknowledged also for providing test slabs and for assisting in DSC measurements.

Last but not least, my gratitude goes to my husband Henrik and daughter Hannie for their moral support and patience.

\section{References}

Abraham H., “Asphalts and allied substances”, vol. 1, Fifth edition, D. Van Nostrand Co. Inc, New York, (1954).

Bahia H. U., Anderson D. A., "Physical Hardening of Paving Grade Asphalts as Related to Compositional Factors", vol. 37, no. 4, Div Fuel Chem., American Chemical Society, Preprints of Papers, 204th ACS National Meeting, Washington DC, (1992).

Barth E. J., "Asphalt, Science and Technology", Gordon and Breach science publishers, New York, London, (1962).

Boucher J. L., "Wax in asphalt - a literature review", prepared for Strategic Highway Research Program by Southwestern Laboratories, Houston Texas, (1991).

Brulé B., Planche J. P., King G., Claudy P., Letoffé J. M., "Relationships between characterization of asphalt cements by differential scanning calorimetry and their physical properties", American Chemical Society Symposium on Chemistry and Characterization of Asphalts, Washington DC, (1990).

Butz T., Rahimian I., Hildebrand G., "Modification of road bitumens with the FischerTropsch paraffin Sasobit", Journal of Applied Asphalt Binder Technology, vol. 1, issue 2, (2001).

Damm K-W., Abraham J., Butz T., Hildebrand G., Riebesehl G., “Asphalt flow improvers as 'intelligent fillers' for hot asphalts - a new chapter in asphalt technology", Journal of Applied Asphalt Binder Technology, vol. 2, issue 1, (2002). 
De Bats F., Hofstra A., “Waxy bitumens”, Shell Bitumen Review 51, (1975).

Edwards Y., Redelius P., "Rheological effects of waxes in bitumen", Energy \& Fuels, vol. 17, pp. 511-520, (2003).

Fritsche H., "Zur Bestimmung des Paraffingehaltes in Bitumen", Bitumen, Heft 4, 1994, pp. 176-178, and "Zur Bestimmung des Paraffingehaltes in Bitumen", Bitumen, Heft 1, pp. 29-33, in German, (1995).

Gawel I., Czechowski F., "Study of saturated components in asphalt", Petroleum Science and Technology, vol. 15 (7\&8), pp. 729-742, (1997).

Gawel I., Czechowski F., "Wax content of bitumens and its composition”, Erdöl Erdgas Kohle, Heft 10, pp. 507-509, (1998).

Hesp S., "Reversible ageing in asphalt at low temperatures. Final report", Queen's University Dep of Chemistry, Kingston Ontario, Canada, (2004).

Iliuta S., Andriescu A., Hesp S., Tam K., "Improved approach to low temperature and fatigue fracture performance grading of asphalt cements". Proceedings of the Canadian Asphalt association, vol. 49, (2004).

Johansson L. S., "Bitumen ageing and hydrated lime”. PhD thesis, TRITA-IP FR 98-38, Kungliga Tekniska Högskolan, Stockholm, (1998).

Krom C. J., "Determination of wax content of bitumen", Journal of the Institute of Petroleum, vol. 54, no. 536, pp.232-240 (1968).

Lee N. K., Hesp S. A. M., "Low temperature fracture toughness of polyethylene-modified asphalt binders", Transportation Research Record No. 1436, (1994).

Létoffé J.M., Claudy P., Garcin M., Volle J. L., "Evaluation of crystallized fractions of crude oils by differential scanning calorimetry. Correlation with gas chromatography", Fuel, vol. 74, pp. 92-95, (1995).

Lu X., Soenen H., Redelius P., "Impact of bitumen wax on asphalt performance - Low temperature cracking", Eurasphalt \& Eurobitume Congress, Vienna, report no. 50 (2004).

McKay J. F., Branthaver J. F., Robertson R. E., "Isolation of waxes from asphalts and the influence of waxes on asphalt rheological properties", Division of Petroleum Chemistry, American Chemical Society 210th national meeting, Chicago, August 20-25, (1995).

Mózes G. (editor), "Paraffin products: properties, technologies, applications", Elsevier Company, Amsterdam-Oxford-New York, (1982).

Musser B. J., Kilpatrick P. K., "Molecular characterization of wax isolated from a variety of crude oils". Energy \& Fuels, vol. 12, pp. 715-725 (1998).

Noel F., Corbett L. W., "A study of the crystalline phases in asphalts", Journal of the Institute of Petroleum, vol. 56, pp. 261-268, (1970).

Obertür U., "Entwicklung einer optischen Methode zur Bestimmung des Paraffingehalts im Bitumen (Glanzmethode) ", Bitumen, Heft 1, pp. 11-18, in German, (1998). 
Planche J. P., Claudy P. M., Létoffé J. M., Martin D., “Using thermal analysis methods to better understand asphalt rheology", Thermochimica acta, vol. 324, p. 223-227 (1998).

Redelius P., Lu X., Isacsson U., "Non-classical wax in bitumen”, International Journal of Road Materials and Pavement Design, vol. 3, issue 1, (2002).

Redelius P. Nynas AB, Nynäs, Personal Communication; (2004).

SHRP-A-369, SHRP report A 369, "Binder Characterization and Evaluation Volume 3: Physical Characterization", (1994).

Soenen H., Ekblad J., Lu X., Redelius P., "Isothermal hardening in bitumen and in asphalt mix", Eurasphalt \& Eurobitume Congress, Vienna, report no. 135 (2004).

Such C., Planque L., Lombardi B., Planche J. P., Gillet J. P., "Les paraffines dans les bitumes", Eurasphalt \& Eurobitume Congress, Barcelona, book 1, pp. 846-854, in French, (2000).

Unterleutner H., Ecker A., Hartner O., "Ermittlung des Gehaltes an Heptan-Unlöslischem und des Paraffingehaltes aus den Ergebnissen der Bitumenanalyse mittels DC-FID". Bitumen, Heft 4, in German (1998).

Van Doorn R., Bitumen Group Shell Global Solutions, Petit Couronne, Personal Communication, (2002).

Warth A. B., "The Chemistry and Technology of Waxes", Reinhold, NY, (1956).

\section{Abbreviations}

AFM

atomic force microscopy

API

american petroleum industry

BBR

bending beam rheometer

BTDC

bitumen test data chart

$\mathrm{CF}$

cold finger

$\mathrm{CF}$

CLSM

$\mathrm{CP}$

crystallizing fraction

CPM

confocal laser scanning microscopy

DMA

cloud point

DSC

cross polarized microscopy

DSR

dynamic mechanical analysis

DT

differential scanning calorimetry

dynamic shear rheometer

DTA

dilatometry

DTG

differential thermal analysis

FI

derivative thermogravimetry

flow improver 
FID

GC-MS

HPLC

HTGC/MS

ICTA

IEC

MEK

MIBK

NMR

PAV

PCM

PHF

PI

PLS

PNA

PP

PPD

PPT

PSEC

PVN

RTFO

SANS

SEC

SEM

SFC

SHRP

TG

TMDSC

TSRST

UOP

WAT

WDT

WPT

ZSV flame ionization detection

gas chromatography - mass spectroscopy

high performance liquid chromatography

high-temperature gas chromatograpy/mass spectroscopy

international confederation of thermal analysis

ion exchange chromatography

methyl ethyl ketone

methyl isobutyl ketone

nuclear magnetic resonance

pressure ageing vessel

phase contrast microscopy

physical hardening factor

penetration index

partial least squares

paraffins naphthenics aromatics

pour point

pour point depressant

pour point temperature

preparative size exclusion chromatography

penetration viscosity number

rolling thin film oven

small angle neutron scattering

size exclusion chromatography

scanning electron microscopy

supercritical fluid chromatography

strategic highway research program

thermogravimetry

temperature modulated differential scanning calorimetry

thermal stress restrained specimen test

universal oil products

wax appearance temperature

wax dissolution temperature

wax precipitation temperature

zero shear viscosity 